$$
18,9095(2)
$$

\title{
Software Quality \\ Assurance Handbook
}

Kansas City Division

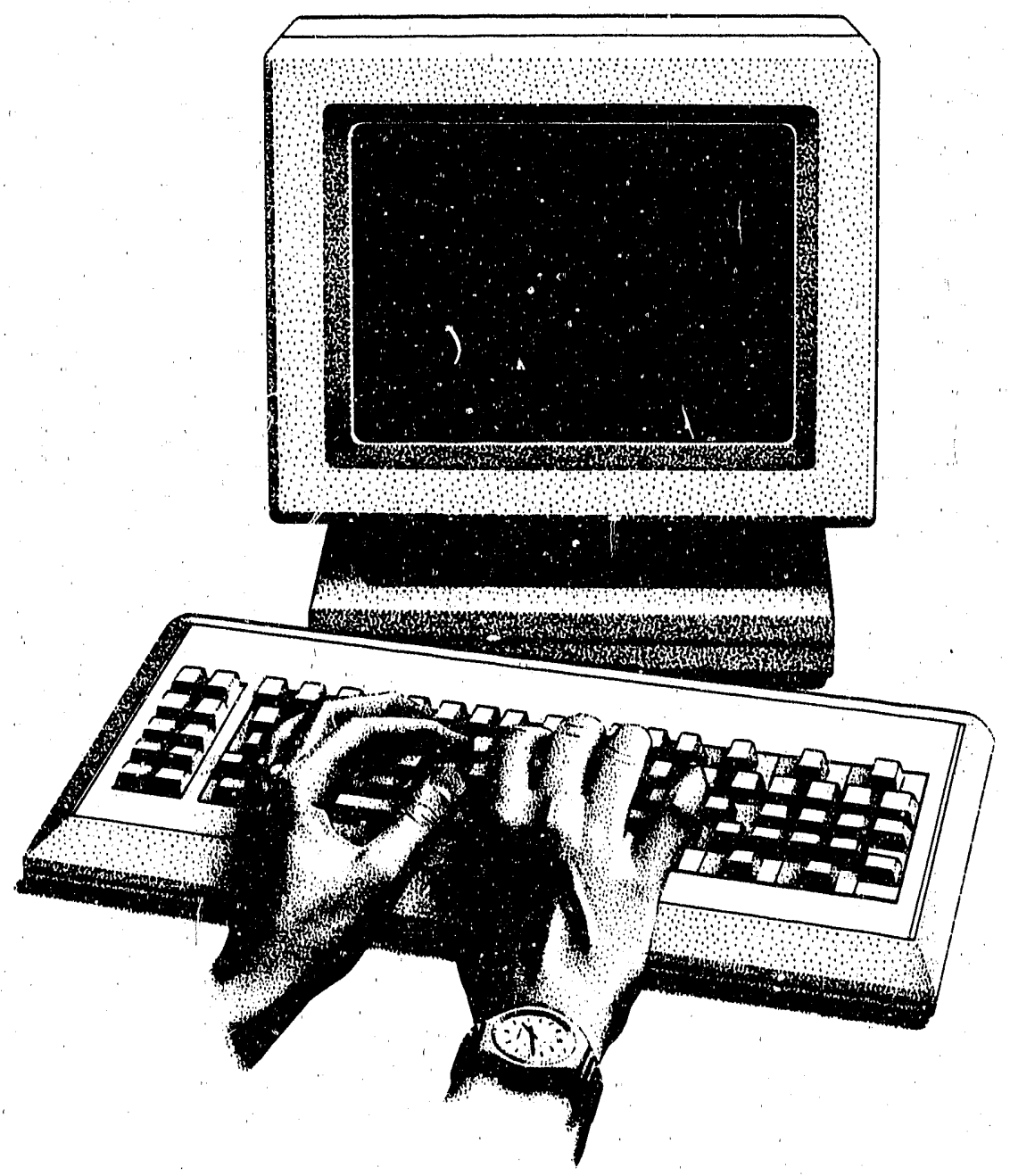

Prepared for the United States Department of Energy Under Contract Number DE-AC04-76-DP00613. 
This report was prepared as an account of work sponsored by an agency of the United States Government. Neither the United States Government nor any agency thereof, nor any of their employees, makes any warranty, express or implied, or assumes any legal liability or responsibilit" for the accuracy, completeness, or usefulness of any information, apparatus, product, or process disclosed, or represents that its use would not infringe privately owned rights. Reference herein to any specific commercial product, process, or service by trade name, trademark, manufacturer, or otherwise, does not necessarily constitute or imply its endorsement, recommendation, or favoring by the United States Government or any agency thereaf. The views and opinions of authors expressed herein do not necessarily state or reflect those of the United States Government or any agency thereof.

Printed in the United States of America.

This report has been reproduced from the best available copy.

Available to DOE and DOE contractors from the Office of Scientific and Technical Information, P.O. Box 62, Oak Ridge, Tennessee 37831; prices available from (615) 576-8401, FTS 626-8401.

Available to the public from the National Technical Information Service. U.S. Department of Commerce, 5285 Port Royal Rd., Springfield, Virginia 22161.

Price Code: Printed Copy A04 Microfiche A01 
$\mathrm{KCP}-613-4118$

Distribution Category UC-706

SOFTWARE QUALITY ASSURANCE HANDBOOK

$\mathrm{KCP}--613-4118$

Software Quality Assurance Group

Publisned September 1990

Technical Communications

Kansas City Division

Allied-Signal Aercspace Company

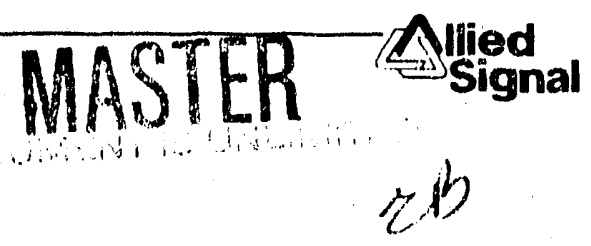




\section{Table of Contents}

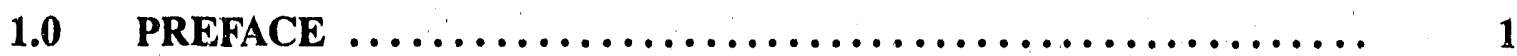

$2.0 \quad$ INTRODUCTION $\ldots \ldots \ldots \ldots \ldots \ldots \ldots \ldots \ldots \ldots \ldots \ldots \ldots \ldots, 3$

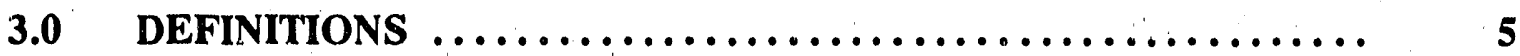

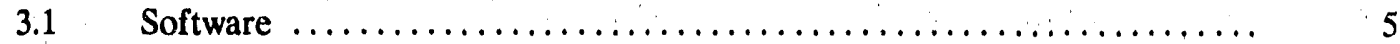

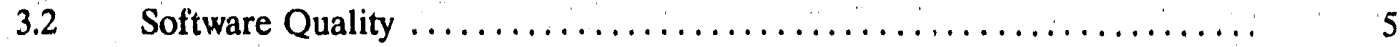

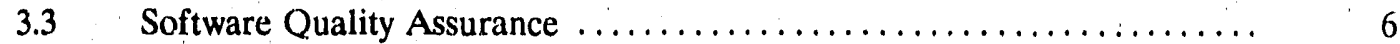

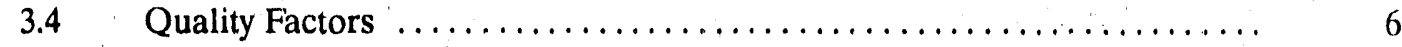

$3.5 \quad$ Life Cycle $\ldots \ldots \ldots \ldots \ldots \ldots \ldots \ldots \ldots \ldots \ldots \ldots \ldots \ldots \ldots \ldots \ldots \ldots \ldots \ldots \ldots$

$3.6 \quad$ Software Development Project $\ldots \ldots \ldots \ldots \ldots \ldots \ldots \ldots \ldots \ldots \ldots \ldots \ldots . \ldots$

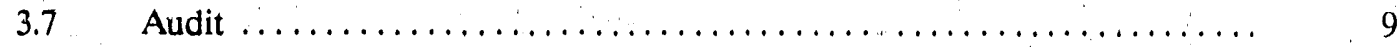

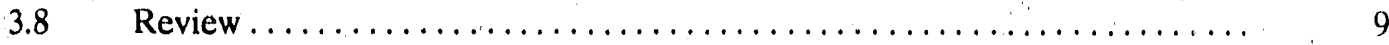

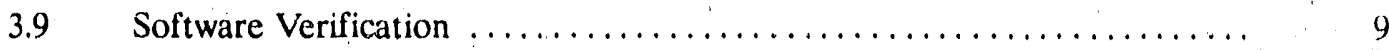

3.10 Software Validation $\ldots \ldots \ldots \ldots \ldots \ldots \ldots \ldots \ldots \ldots \ldots \ldots \ldots \ldots \ldots$

4.0 CONCEPTS $\ldots \ldots \ldots \ldots \ldots \ldots \ldots \ldots \ldots \ldots \ldots \ldots \ldots \ldots \ldots \ldots \ldots \ldots \ldots \ldots, 11$

$4.1 \quad$ Benefits $\ldots \ldots \ldots \ldots \ldots \ldots \ldots \ldots \ldots \ldots \ldots \ldots \ldots \ldots \ldots \ldots \ldots \ldots \ldots$

$4.2 \quad$ Roles $\ldots \ldots \ldots \ldots \ldots \ldots \ldots \ldots \ldots \ldots \ldots \ldots \ldots \ldots \ldots \ldots \ldots \ldots \ldots \ldots \ldots, \ldots \ldots \ldots$

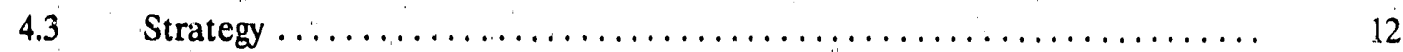

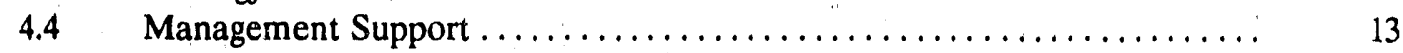

4.5 Software Metrics $\ldots \ldots \ldots \ldots \ldots \ldots \ldots \ldots \ldots \ldots \ldots \ldots \ldots \ldots \ldots \ldots \ldots . \ldots$

5.0 DOCUMENTATION $\ldots \ldots \ldots \ldots \ldots \ldots \ldots \ldots \ldots \ldots \ldots \ldots \ldots \ldots, 15$

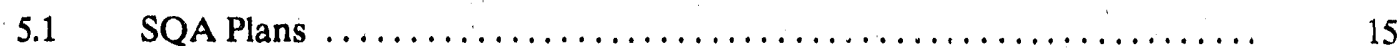

$5.1 .1 \quad$ Useful Plans $\ldots \ldots \ldots \ldots \ldots \ldots \ldots \ldots \ldots \ldots \ldots \ldots \ldots \ldots \ldots \ldots \ldots$

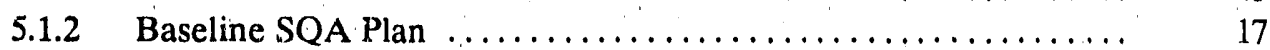

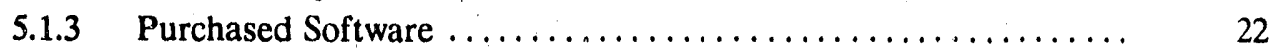

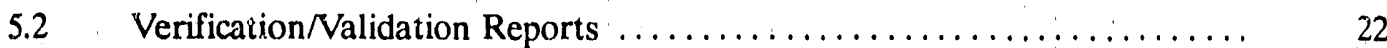

$5.3 \quad$ Acceptance Test Plan $\ldots \ldots \ldots \ldots \ldots \ldots \ldots \ldots \ldots \ldots \ldots \ldots \ldots \ldots \ldots \ldots \ldots . \ldots$

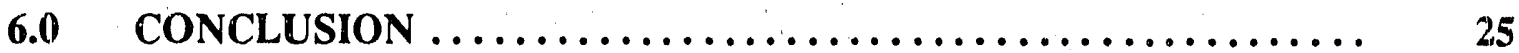

\section{Appendices}

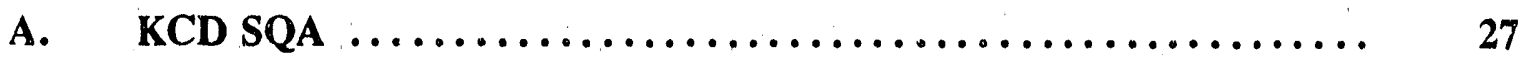

B. QUALITY FACTORS $\ldots \ldots \ldots \ldots \ldots \ldots \ldots \ldots \ldots \ldots \ldots \ldots \ldots, 29$

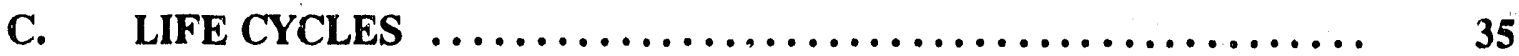

C.1 Thought Processes Versus Documentation Processes ............ 35

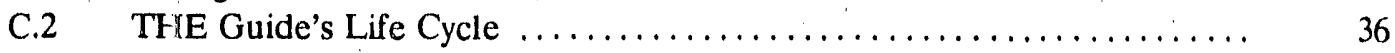

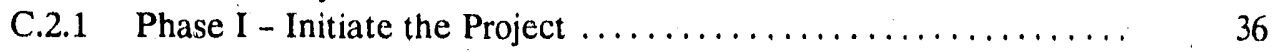

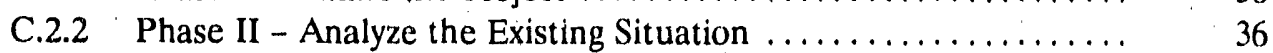

C.2.3 Phase III - Define New System Requirements ... . . . . . . . . . . 37 


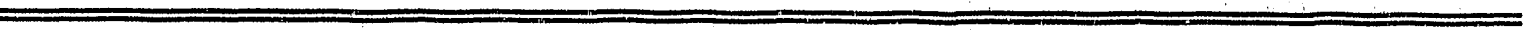

C.2.4 Phase IV - Design the Logical System $\ldots \ldots \ldots \ldots \ldots \ldots \ldots \ldots \ldots \ldots$

C.2.5 Phase V-Design the Physical System ................. 38

C.2.6 Phase VI - Construct the System ................... 39

C.2.7 Phase VII - Test and Implement System . . . . . . . . . . . . . . 39

C.2.8 Phase VIII - Using the System .................... 40

C.2.9 Phase IX - Maintenance $\ldots \ldots \ldots \ldots \ldots \ldots \ldots \ldots \ldots \ldots \ldots \ldots . \ldots \ldots$

D. SQA TEAM $\ldots \ldots \ldots \ldots \ldots \ldots \ldots \ldots \ldots \ldots \ldots \ldots \ldots \ldots \ldots, 41$

D.1 Structure $\ldots \ldots \ldots \ldots \ldots \ldots \ldots \ldots \ldots \ldots \ldots \ldots \ldots \ldots \ldots \ldots \ldots \ldots \ldots \ldots \ldots ., 41$

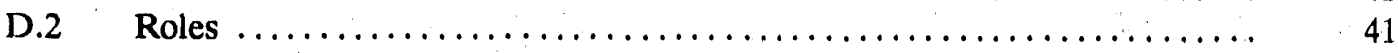

E. ACCEPTANCE TEST TEAM $\ldots \ldots \ldots \ldots \ldots \ldots \ldots \ldots \ldots \ldots, 43$

E.1 Structure $\ldots \ldots \ldots \ldots \ldots \ldots \ldots \ldots \ldots \ldots \ldots \ldots \ldots \ldots \ldots \ldots \ldots \ldots \ldots \ldots$

E.2 Roles $\ldots \ldots \ldots \ldots \ldots \ldots \ldots \ldots \ldots \ldots \ldots \ldots \ldots \ldots \ldots \ldots \ldots \ldots \ldots \ldots \ldots \ldots$

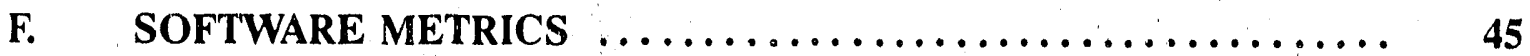

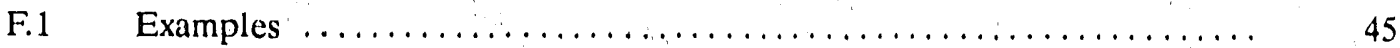

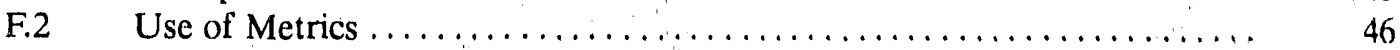

G. REVIEW PROCEDURES ....................... 47

G.1 General Review Procedures $\ldots \ldots \ldots \ldots \ldots \ldots \ldots \ldots \ldots \ldots \ldots \ldots \ldots \ldots \ldots .47$

G.2 Specific Reviews $\ldots \ldots \ldots \ldots \ldots \ldots \ldots \ldots \ldots \ldots \ldots \ldots \ldots \ldots \ldots \ldots \ldots \ldots \ldots$

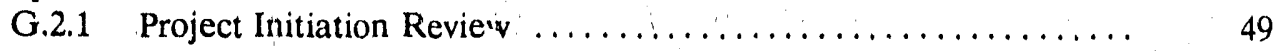

G.2.2 Context Analysis Review ..................... 49

G.2.3 New Systems Requirements Review .................. 50

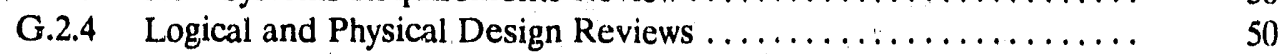

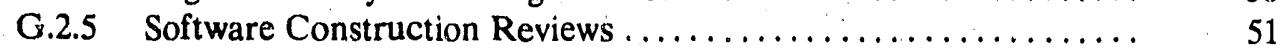

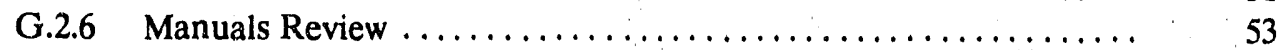

G.2.6.1 Client Manual Reviews ................... 53

G.2.6.2 Maintenance Guide Review ............... 54

G.2.7 Test Plan Reviews $\ldots \ldots \ldots \ldots \ldots \ldots \ldots \ldots \ldots \ldots \ldots \ldots \ldots \ldots$

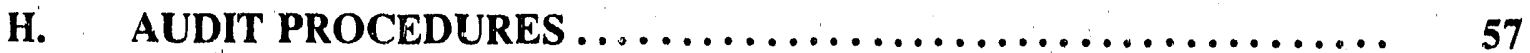

H.1 General Audit Procedures $\ldots \ldots \ldots \ldots \ldots \ldots \ldots \ldots \ldots \ldots \ldots \ldots \ldots \ldots \ldots \ldots . \ldots \ldots$

H.2 Specific Audits $\ldots \ldots \ldots \ldots \ldots \ldots \ldots \ldots \ldots \ldots \ldots \ldots \ldots \ldots \ldots \ldots \ldots \ldots, 58$

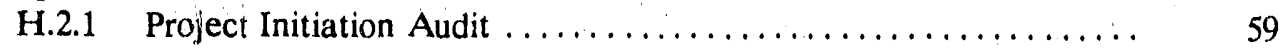

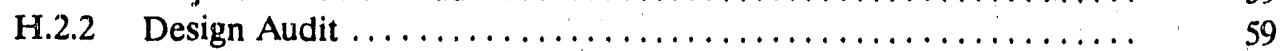

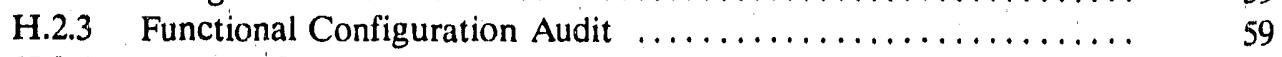

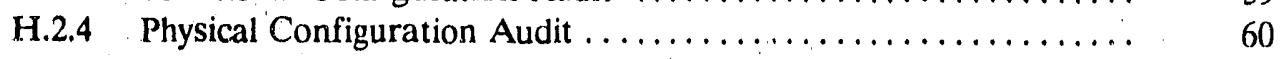

I. ACCEPTANCE TESTING PROCEDURES $\ldots \ldots \ldots \ldots \ldots \ldots \ldots \ldots, 61$

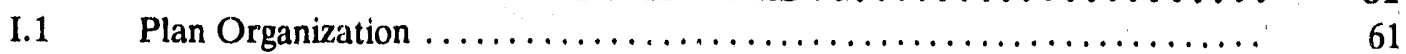

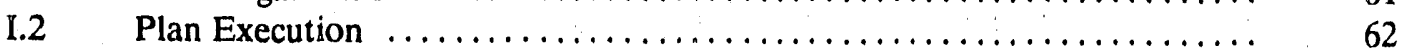

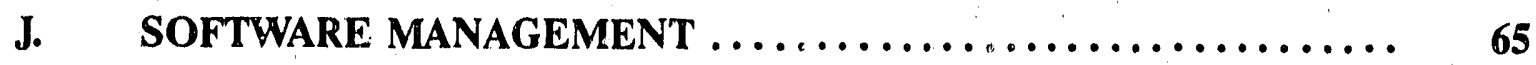

J.1 Software Configuration Management (SCM) $\ldots \ldots \ldots \ldots \ldots \ldots \ldots \ldots \ldots \ldots 6$

J.2 Problem-Reporting Procedures $\ldots \ldots \ldots \ldots \ldots \ldots \ldots \ldots \ldots \ldots \ldots \ldots \ldots . \ldots \ldots$

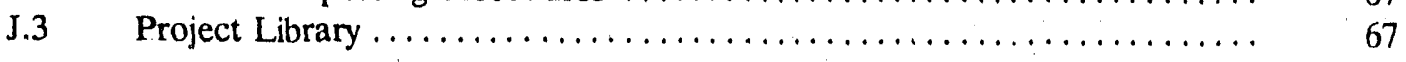

K. PURCHASED SOFTWARE $\ldots \ldots \ldots \ldots \ldots \ldots \ldots \ldots \ldots \ldots \ldots \ldots, 69 \ldots \ldots$

K.1 Packaged Software with No Modifications ...................... 69 
K.2 Packaged Software With Some Modification $\ldots \ldots \ldots \ldots \ldots \ldots \ldots \ldots, 69$

K.3 Vendor-Supplied Custom Software ........................ 70

L. THE COMMUNICATION PROCESS .................... 71

L.1 Improving Interpersonal Communications $\ldots \ldots \ldots \ldots \ldots \ldots \ldots \ldots, 71$

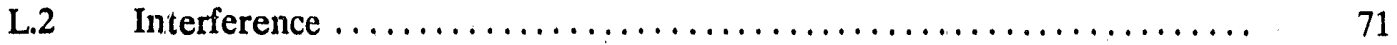

L.3 Feedback $\ldots \ldots \ldots \ldots, \ldots \ldots \ldots \ldots \ldots \ldots \ldots \ldots \ldots \ldots \ldots \ldots \ldots \ldots, \quad 73$

M. KCD SQA POLICY $\ldots \ldots \ldots \ldots \ldots \ldots \ldots \ldots \ldots \ldots \ldots \ldots \ldots, 75$

N. BIBLIOGRAPHY $\ldots \ldots \ldots \ldots \ldots \ldots \ldots \ldots \ldots \ldots \ldots \ldots \ldots \ldots \ldots \ldots \ldots \ldots$

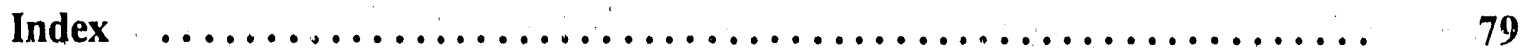




\subsection{PREFACE}

There are two important reasons for Software Quality Assurance (SQA) at Allied-Signal Inc., Kansas City Division (KCD): First, the benefits from SQA make good business sense. Second, the Department of Energy has requested SQA.

This handbook is one of the first steps in a plant-wide implementation of Software Quality Assurance at KCD. Everyone involved with the development, procurement and use of software should read and use this handbook. It was developed by the KCD SQA Group. (See Appendix A, KCD SQA, for more information.) The handbook has two main purposes. The first is to provide information that you will need to perform software quality assurance activities. The second is to provide a common thread to unify the approach to SQA at KCD.

In concept, the scope of the handbook includes all software used at KCD. Whether it is purchased, developed in-house, a new application, or maintenance of an existing system, the handbook provides ideas and suggestions that may be effectively applied in each of these cases. The SQA effort, however, should be consistent with the need for assurance and the type of software. For example, small projects -- which involve fewer people -- require less formality (and proportionally less effort) for SQA than large projects. Software used for critical applications, such as software on automated testers, requires more formality, while purchased software packages used in non-critical applications require less.'

The handbook is intended to mature as the implementation of SQA at KCD matures. As appropriate new approaches and technology are identified, they will be incorporated into the handbook. The SQA Group welcomes suggestions for changes to the handbook which will enhance its usefulness and effectiveness.

The handbook is not intended to be a procedure to be followed religiously, nor will it provide the "magic pill" that will quickly solve all software problems. The handbook does not replace good software engineering practices, but rather depends on such practices to be effective and beneficial.

The SQA Group would like to acknowledge the assistance of Mr. Ed Mangiaratti (ITP boston, inc.). His contributions were instrumental in the preparation of this handbook. 


\subsection{INTRODUCTION}

This handbook defines a set of ideas that KCD can use as a guide in its Software Quality Assurance (SQA) activities. The handbook provides a detailed description of the processes and methods for performing SQA and can be used as a daily reference guide. The handbook should be read and used by anyone who needs to be concerned with the software quality process during the acquisition, development, and maintenance of a system; that is, by developers, managers, clients, vendors, and quality teams.

Developing quality software requires everyone's involvement. Anyone who has faced the challenge of developing a software system understands that the task of producing quality software is harder than it appears, and certainly harder than the client thinks it should be. The road to functional software is filled with many pitfalls and the risk of failure is significant.

Much of the difficulty and part of the challenge of developing software stem from its intangibility; a person can't simply draw a blueprint or describe its physical characteristics. Although the process of developing software borrows much from established engineering disciplines, some of the process remains undefined.

Software developers often have strong convictions about the proper mix of engineering and art, but these vary from person to person. At KCD, sharing a consistent set of ideas about what constitutes software quality and using consistent methods to achieve that end are critical to a successful product. These ideas and methods also play an important part in making a project successful.

As we will discuss in this handbook, the benefits of SQA are very real. We strive for better software quality and for consistency in the engineering process to lower the risk of failure. Developing software may never become easy. If, however, we improve the process for development and the methods for checking quality, we can significantly raise the level of success that can be achieved.

Conducting a software quality assurance program can significantly reduce the number of errors introduced into the software product and ensure that more errors are detected earlier in the system development life cycle.

The handbook is organized into two main parts. The first is a generic SQA model that is appropriate for both managers and technical staff. The second part contains more details and is included as appendices. 


\subsection{DEFINITIONS}

\subsection{Software}

Software - According to the IEEE Standard 729-1983, software is "computer programs, procedures, rules, and possibly associated documentation and data pertaining to the operation of a computer system."

Note: the definition of software includes not only the computer code, but also the documentation that goes with it. This definition encompasses both in-line comments in the code as well as specifications, design documents, client manuals, and maintenance guides. Good software must not only work well but must be ciocumented well, too.

\subsection{Software Quality}

Software Ouality - The SQA literature defines software quality as the ability of the software to comply with defined requirements.

This differs from a definition based on the fitness for use of the software. This definition of quality as compliance with defined requirements places anyone involved in SQA in the position of operating with something other than opinion and experience. Defined requirements act as the foundation for determining the level of quality. Emphasis therefore needs to be placed on establishing the requirements in the first place rather than on determining what to do after the damage is done and the system works inadequately.

This definition of quality implies two areas of action for the SQA function:

1. Ensure that the product correctly meets client needs.

2. Verify that reasonable steps were taken to ensure the quality of the product.

These two areas imply that a system must also meet a number of software quality factors or characteristics, in addition to performing its general processing function. (See the sections pertaining to Quality Factors and Appendix B for more information.)

As previously mentioned, the goal of quality is to meet specified requirements rather than achieve an absolute level of quality. The purpose is not to guarantee $100 \%$ reliability or zero defects; rather, it is to verify that every reasonable step has been taken during the life cycle to achieve a desired level of quality in the end product. 


\subsection{Software Quality Assurance}

Software Ouality Assurance (SQA) - According to the IEEE standard P730, SQA is "a planned and systematic set of actions that provide confidence that the software conforms to established technical requirements." This definition encompasses two points.

1. SQA includes all necessary activities that can contribute to the quality of software during the entire life cycle of the project.

2. The emphasis must be on developing and systematically executing the Plan to achieve the objectives of software quality. The emphasis should be on techniques that have been demonstrated to be effective in practice.

\subsection{Quality Factors}

Quality Factors - the general categories that inherently characterize the nature of a software project's quality. Quality factors can be grouped according to performance, design, or adaptation concerns.

Performance quality factors characterize how well the software functions. The performance factors are efficiency, integrity, reliability, survivability, and usability.

Design quality factors characterize the software design. The design factors are correctness, maintainability, and verifiability.

Adaptation quality factors characterize the adaptability of the software. The adaptation factors are expandability, flexibility, interoperability, portability, and reusability.

1. Efficiency - the amount of computing resources and code required by the software to perform a function.

2. Integrity - the extent to which access to software or data by unauthorized persons should be controlled.

3. Reliability - the extent tc which the software performs its intended function without failures for a given time period.

4. Survivability - the extent to which the software will perform and support critical functions when a portion of the system is inoperable.

5. Usability - the effort required to learn, operate, prepare input, and interpret output of the software. 
6. Correctness - the extent to which the software satisfies its specifications and fulfills the clients' objectives.

7. Maintainability - the effort required to locate and fix an error in the operational software.

8. Verifiability - the effort required to test and verify that the software performs its intended function.

9. Expandability - the effort required to increase the software capability or performance by enhancing current functions or by adding new functions or data.

10. Flexibility - the effort required to modify operational software.

11. Pprtability - the effort required to transport the software for use in anorher euvironment.

12. Reusability -- the extent to which the software can be used in other applications.

13. Interoperability - the effort required to couple the software of one system to the software of another system.

SQA uses these quality factors to determine the extent that the project is satisfying its quality objectives. A more detailed discussion of each factor is contained in Appendix B, Quality Factors.

\subsection{Life Cycle}

Life Cycle - A development process composed of a number of stages that are broken into deliberate steps. Life cycles vary depending on the organization using them and the nature of the software being developed. All software development life cycles exhibit similar characteristics, regardless of what the specific stages are called, or the format of the documentation that results. The stages are as follows.

Requirements Includes understanding the target environment and gathering and analyzing the requirements.

Design

Includes both the logical and physical aspects of the system.

Implementation Includes defining the details of the design, coding the system, testing it, and installing it. 


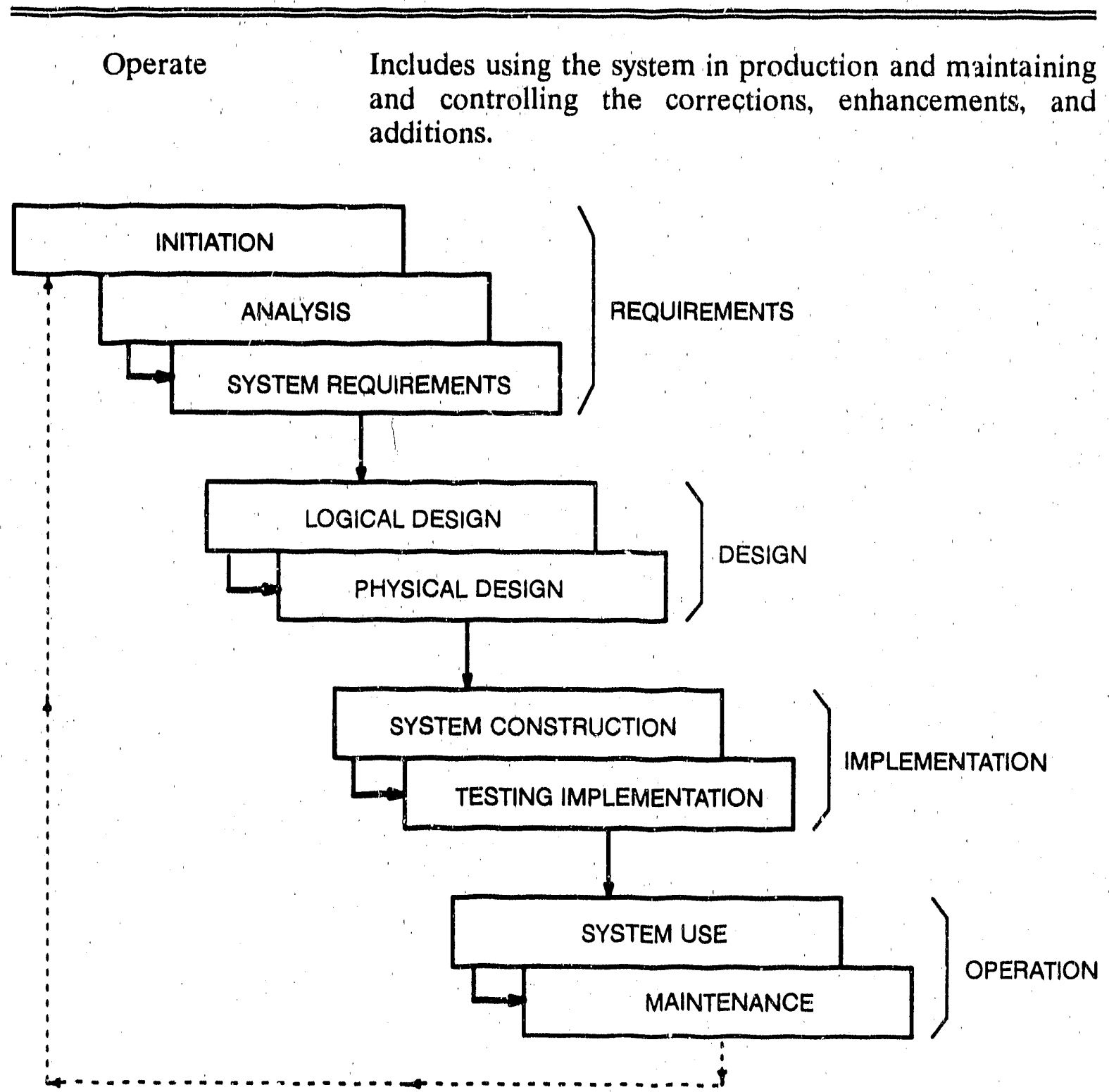

Figure 1. Life Cycle

An example of such a life cycle that uses a structured development methodology is defined in the Myers \& Associates publication, THE Guide (a software development life cycle model). THE Guide defines its system development life cycle in nine phases illustrated in Figure 1.

THE Guide is currently being used at KCD; refer to the Appendix C, Life Cycles, and THE Guide Manuals for more details. 


\subsection{Software Development Project}

Software Development Project - The overall task of producing a software system. A project may be procurement of the desired software, an internal development effort in the usual sense, or a combination of the two. A project is initiated and managed in order to deliver the software system but will generate additional deliverables such as specifications, design documcints, test plans, and client manuals.

\section{7 $\quad$ Audit}

Audit - An inspection of the documents and associated development methods to verify that the process and its documentation are in accordance with the SQA Plan and organizitional policies and procedures.

\subsection{Review}

Review - A study of the documentation or code. Its purpose is to evaluate the conceptual and technical approach to the system solution and ensure that the quality factors previously defined for the project are satisfied. A review attempts to identify problems before they appear as errors in the software product.

\subsection{Software Verification}

Software Verification - According to the IEEE Standard 729-1983, software verification is "(1) The process of determining whether or not the products of a given phase of the software development cycle fulfill the requirements established during the previous phase. (2) Formal proof of program correctness. (3) The act of reviewing, inspecting, testing, checking, auditing, or otherwise establishing and documenting whether or not items, processes, services, or documents conform to specified requirements. (ANSI/ASQC A3-1978)."

In other words, "Are we building the product right?"

\subsection{Software Validation}

Software Validation - According to the IEEE Standard 729-1983, software validation is "the process of evaluating software at the end of the software development process to ensure compliance with software requirements."

In other words, "Are we building the right product?" 


\subsection{CONCEPTS}

\subsection{Benefits}

Software Quality Assurance activities are an important part of consistent software engineering practices. Consistency in SQA and software engineering

- Lowers the risk involved with developing software systems;

- Draws upon the experiences of previous projects;

- Structures the activities of development;

- Improves the value and predictability of deliverables;

- Encourages continual improvement of the development process; and

- Provides the opportunity to measure the improvement of the development process.

This raises the level of success that software projects will achieve.

\subsection{Roles}

SQA activities involve four groups at $\mathrm{KCD}$.

- The KCD SQA Group.

- The Project Team.

- The Acceptance Test Team.

- The Software Quality Assurance (SQA) Team.

The KCD SQA Group is part of the Quality Organization. It acts as an advisory and monitoring group to aid Project Teams, Acceptance Test Teams, and SQA Teams in providing proper SQA at KCD.

The Project Team consists of the person or persons responsible for the project activities. It is responsible for delivering the final system and keeping track of all the associated documentation which was created during the project's life cycle.

The Acceptance Test Team deals with the Acceptance Test Plan. They are responsible for its creation, its execution, and the resulting documentation.

The SQA Team is concerned with the activities which deal with software quality assurance and the associated documentation which is created. 
These teams represent the primary roles in every software project. The planning activities identify the structure and personnel for the teams and specify the roles, activities, and documentation in detail. The teams will always exist but must be staffed according to the scope and complexity of the project. The roles tell the tearn members the proper perspective in performing those team activities. Projects involving only a few people will assign the members to several roles across the teams. If a project has only one person assigned, he or she will play all roles! It is difficult to play all roles on a single project, so this extreme should be avoided.

For more information about the roles, see the section on Documentation and the following appendices:

Appendix A, KCD SQA, Appendix D, SQA Team, and

Appendix E, Acceptance Test Team.

\subsection{Strategy}

An SQA strategy consists of a basic set of procedures and activities designed to emphasize the quality of software at KCD. Figure 2 shows the minimum set, of eight elements necessary to define the project and SQA activities and to provicie for defect analysis as a means of continuous quality improvements. This diagram represents a development or enhancement effort at KCD and is relevant to any size project in any type of environment. This Handbook deals specifically with the "how to" of items 3 and 4 on the diagram. In addition to development and enhancement, the day-to-day maintenance of an existing system is represented by elements 5 through 8 on the diagram.

From an SQA point of view, the most important data needed to measure and manage quality improvements is defect-based. More specifically, reporting of defects on a timely basis can be used by the Project Team to improve the software product they are building. Analysis of defects can be used by management to objectively determine training needs and support their decisions concerning changes in technology. Summary reports to management can show that continuous improvements in software quality is a reality that can be measured. 
1. PROCEDURES (to point to proper life cycle)

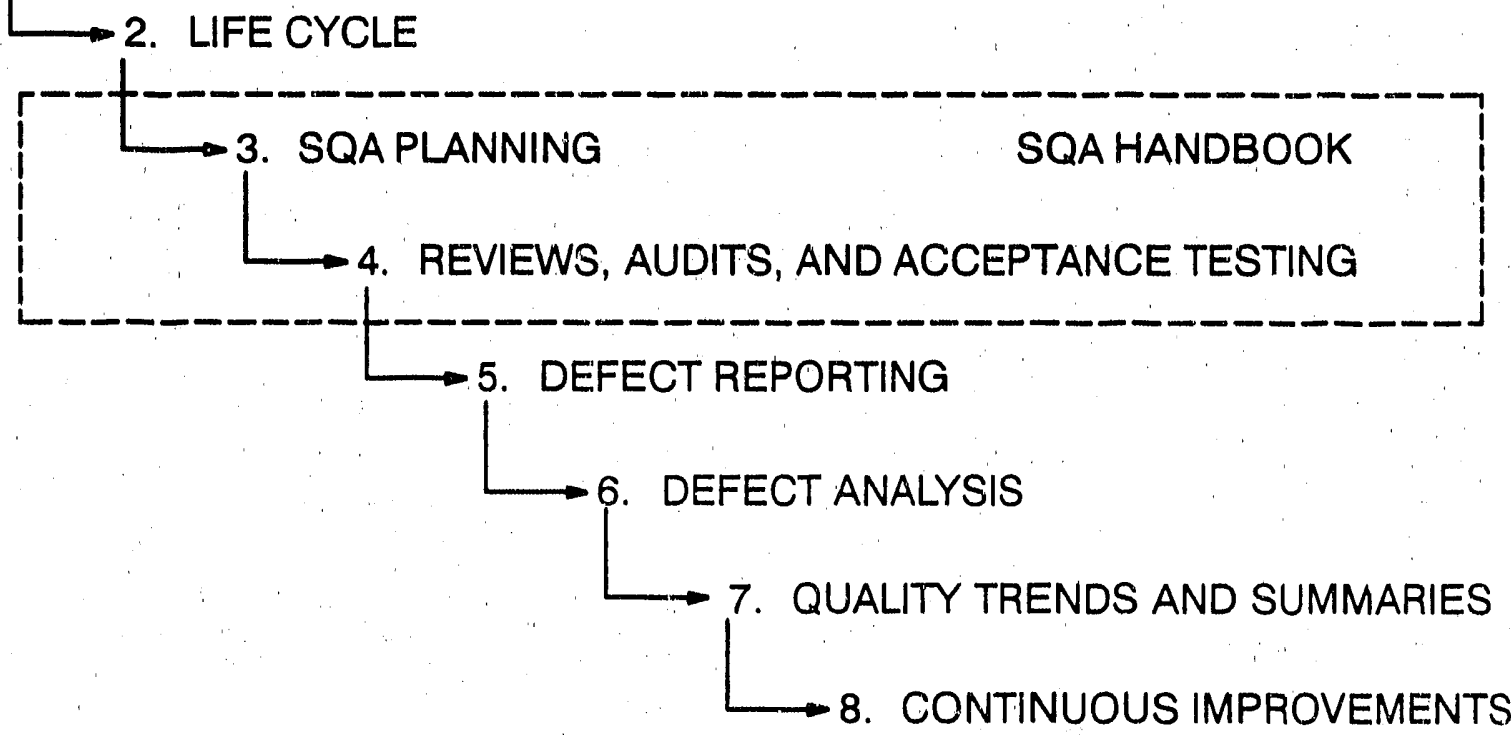

Figure 2. Software Quality Strategy

\subsection{Management Support}

Management plays an important part in the level of success that an SQA Tearn can achieve on a project. Effective SQA requires effective management. Management will need to work with their staff and the SQA Group to ensure that all elements in the SQA strategy diagram are established and followed at KCD. Management supports SQA by

nI Supporting the consistent use of SQA principles by all involved, and

v Supporting the staff, including the SQA Team, in the following areas:

1. Understanding software engineering and SQA methods,

2. Communicating well--defined requirements to SQA Team members in order to achieve quality,

3. Realizing the level of commitment required for SQA to work (including adequate resources and training),

4. Charging the SQA staff with both the responsibility and authority to carry out the SQA Plan, and

5. Fostering advisors who serve as technical experts to the rest of the staff.

Likewise, the SQA staff support management through the following: 
1. Presenting to their management solutions to problems as well as problems;

2. Defining what constitutes quality for a given project (relates to presenting solutions);

3. "Stating clearly in the project plan what resources will be required; and

4. Requesting the authority to halt development if a serious problem occurs.

This is a new way of doing business and may be filled with numerous false starts. Management needs to be patient, but still encourage the SQA efforts.

\subsection{Software Metrics}

Software metrics is the process of measuring software quality. The intent is to show the correlition between software engineering methods and improved software quality. The long-tern goal is to see how different SQA procedures and structured development methods affect the overall quality that can be achieved. By collecting metric data, improvements in quality can be measured. Such quality metrics are important because it is difficult to manage and improve what is not measured. See Appendix F, Software Metrics, for examples of several types of metrics. 


\subsection{DOCUMENTATION}

The system development project produces three types of documentation.

- The Project Team produces the project deliverables required for the project. The deliverables are the many different forms of the software as it progresses through the life cycle.

- The Acceptance Test Team produces the Acceptance Test Plan.

- The SQA Team produces an SQA Plan and a set of Verification/Validation Reports. This latter documentation provides the quality assurance for the project.

Two concepts that are often confused are SQA Plans and Acceptance Test Plans. An SQA Plan defines activities associated with munitoring the project's development from start to finish. An Acceptance Test Plan contains sets of test cases to accept the newly completed, installed system.

\subsection{SQA Plans}

As stated earlier, part of the SQA function is to develop an SQA Plan. The contents of the SQA Plan identify the strategy and supporting activities that will be used to verify quality on the project. There are two basic elements to any SQA Plan: the requirements for SQA documentation and the procedures for quality assurance. In this manner, the plan communicates to the Project Team the expectations for quality on the project and directs the assurance activities of the SQA Team.

\subsubsection{Useful Plans}

Creating a useful SQA Plan is important. This may seem obvious, but many plans fall short in their ability to provide useful information. An SQA Plan requires much care and effort if it is to be useful, rather than simply fulfilling chapter heading requirements. When appropriate SQA activities are integrated into a structured development methodology (such as THE Guide), a separate document containing the SQA Plan may not be required.

A useful SQA plan will exhibit two important characteristics:

1. It should make use of existing structure such as

- The life cycle to be used, 
- Any development tools and techniques to be used,

- Documentation to be generated, and

- Metrics to be reported.

2. It will strive to answer the questions that an SQA Team member has while performing software quality assurance activities. The following are typical areas to address:

- What is the specific software covered by the SQA Plan?

- What is the life cycle that is being used?

- What are the deliverables that must be checked?

- What are the Quality Factors?

- What are the activities that the SQA Team members perform?

- What reports must be completed?

Construction of the plan should recognize that more than one type of reader will use the Plan:

Software Developers - need to know the quality requirements so that they can incorporate them into the design.

Test Plan Developers - need to know the quality factors for which they should develop tests.

Vendors - need to know what quality factors can affect the products and services they are providing on the project.

Managers - need to know what resources are to be applied to the SQA activities and what level of quality can be expected from their staff.

Clients - need to be assured that the right level of quality is defined for their project and that the appropriate steps are being taken to ensure quality.

SOA Team Members - need to know what SQA activities must be performed.

The plan should tnake readily available the expectations and responsibilities for each of these groups. 


\subsubsection{Baseline SQA Plan}

This section on generic SQA planning lays out the structure and important points that should go into every SQA Plan. The objective of an SQA Plan is to inform the reader about the project being planned, what its development stages are, and what quality assurance activities will be applied at each stage. This enables the various people involved in the project to understand the role of software quality assurance. It should also provide direction to each of the parties. They should all find what they need to plan their involvement in the SQA activities during the project's development.

Typically, an SQA Plan contains the following sections:

Introduction,

Project Description,

Project Life Cycle,

Deliverables, Quality Factors,

Revieivs,

Audits,

Adceptance Testing, and

Software Management.

The following pages provide more detail about the SQA Plan. Typically, every section in the SQA Plan, as defined above, exists for a specific project's SQA Plan regardless of the project size. However, the SQA Team and management has flexibility in determining the relevance of each section and including only those sections that make sense.

\section{Introduction}

The Introduction of an SQA Plan should provide the background material for the reader. The reader should understand what the SQA Plan is and who are the people involved. It should therefore cover four key areas:

1. Purpose - define the name of the Plan, why it is being developed, and who will benefit from the Plan.

2. List of references - assuming that something has been written about the project (that is, an RFP or RFQ, a specification, working papers). It is important that the reader be aware of these documents.

3. SQA management organization - describe who is involved with the SQA activities. If an SQA Team has been organized for the project, list the members and their positions. Describe the roles of the SQA Team members. Identify the SQA Administrator for the project. 
4. Approach - describe the philosophy, approach, and organization of the remaining sections of the SQA Plan. Remember, whatever the approach, the goal is that the SQA Plan be useful.

\section{Project Description}

The project description gives the reader an overview of the technical background, concepts, and terminology associated with the project. Typically this section includes a brief introduction and an overview description of the system under development.

It should briefly describe the objectives of the project and list its primary requirements. The list of requirements is important because it can be used as a guide for the organization of the Acceptance Test Plan.

\section{Appropriate Life Cycle}

The project life cycle section of the SQA Plan plays an important part in the organization of the rest of the Plan. Determining the life cycle stages provides the foundation for planning resources and activities for a project; in the same way, that determination affects the structure of the SQA activities.

It is important that the life cycle of a project be defined very early. From there, the SQA activities can be defined. This means that the SQA Team activities do not necessarily exist for each phase of the life cycle. SQA activities could follow the generic life cycle defined in THE Guide.

The SQA Team's activities will be based upon the deliverables made available to them from the project's life cycle. The more deliverables to which the SQA Team has access, the better SQA can be applied. Ideally, all of the life cycle's documentation should be made available to the SQA Team.

In some cases, the SQA Team's access to the deliverables is somewhat limited. For example, in the case of a vendor-supplied system, the SQA Team only has access to the final delivered system and its Client Manuals. Regardless of the situation, the developers of the SQA Plan should describe the specific life cycle as they see it and as it will be used for directing the SQA activities.

\section{Deliverables}

The Deliverables section provides a description of the documents that will be produced and will require checking by the SQA Team. The project's life cycle determines the set of deliverables that will be made available to the SQA Team. These deliverables help define the SQA activities. 
Delivered documents tend to cover both hardware and software. However, the SQA Plan should be primarily concerned with the software. Typically, the "Deliverables" section of the SQA Plan contains the following items:

A brief introduction - list the documents that will be produced during project development that the SQA Team will review.

- Document overview - provide a brief overview of each document and where it fits in the life cycle.

In addition to the technical specifications, be sure to describe all the client manuals, maintenance guides, test plans, and project plans that are included in the set of deliverables.

Typical documentation that is doveloped for a project is referred to by many different names. THE Guide describes some of those. In general, documentation exists in the following categories:

- Requirements definition,

- Functional specifications,

- Architectural design specifications,

- Detailed design specifications,

- Source code,

- Client's manuals,

- Maintenance guides, and

- Project plan.

\section{Quality Factors}

Early in the life cycle of a project, the primary quality concerns and objectives are determined. Those concerns and objectives are defined as quality factors. These quality factors are used as categories to determine the extent of a software project's quality.

This section of the SQA Plan identifies the primary quality factors to be applied to the project. Typically, the SQA Team meets with project developers, project management, testing team, client management, and vendor management to decide which of the quality factors should be given primary emphasis. At this time, the level or degree to which each factor will exist must also be decided. The factors are not all of equal importance. For each project, the factors that will be emphasized should be identified.

For example, the quality factors of maintainability and expandability will be important if the system can be expected to have a long life cycle. Flexibility, reusability, and expandability are important for systems with a high rate of change. Real-time applications siould consider efficienry, reliability, and correctness. The factor of integrity is critical for systems processing classified information. Correctness, integrity, reliability, and verifiability are important factors when considering accounting or payroll applications, for example. 
For each quality factor, describe the factor and the extent to which it should exist, and provide examples. This enables the Project Team to understand the extent of the factors and determine how they affect the design. The important point here is that the quality factors do not apply equally to all projects.

Using the set of quality factors defined in Appendix B, the SQA Team can check for the adequacy of the deliverables in both the software and its related documentation. These quality factors play a critical part in determining the adecuacy of a project's quality and are used as guides when the SQA Team performs any reviews, audits, or testing. The Boeing Metrics can help the SQA Team do that (see Bowen, Wigle, and Tsai, "Specifications of Software Quality Attributes").

\section{Reviews}

The Review section of the SQA Plan should briefly describe the activities that will take place pertinent to the SQA review process. The main areas to address in the review section are these:

- Definition of a review - for those readers not familiar with the activity;

- Review procedures - general review procedures defining what the typical activities are for each of the anticipated reviews on the project; and

- Review list - a list of the reviews that are expected to take place. State the document to be reviewed and the life cycle phase when it will be created.

See Appendix G, Review Procedures, for more details on conducting reviews.

\section{Audits}

The Audit section of the SQA Plan should briefly describe the activities that will take place pertinent to the SQA audit process. The main areas to address in the Audit section are these:

- Definition of an audit - for those readers not familiar with the activity;

- Audit procedures - general audit procedures defining what the typical activities are for each of the anticipated audits on the project; and

- Audit list - a list of the audits that are expected to take place. State the name of the audit, its particular objectives, and the life cycle phase when it will occur. 
See Appendix H, Audit Procedures, for more details about Audits.

\section{Acceptanc: Testing}

The Acceptance Testing section of the SQA Plan briefly describes the activities that will take place pertinent to the SQA acceptance testing process. The main areas to address in the Acceptance Testing section are these:

- Definition of acceptance testing - brief overview of acceptance testing for those readers not familiar with the activity;

- Testing procedures - general acceptance testing procedures describing what the typical activities are during acceptance testing;

- Testing team members - identify the parties involved with the acceptance testing; and

- Reporting procedures - description of the test result reporting and tracking procedures.

See Appendix I, Acceptance Testing Procedures, for more details on performing Acceptance Testing.

\section{Software Management}

The Software Management section of the SQA Plan should briefly describe the policies and procedures associated with managing and coordinating the software. Those policies and procedures apply to the project both in development and after the system has been installed and is in production. There are three main areas to address in the Software Management section.

- Software Configuration Management (SCM) - Identify the documents that will be used as baselines for change control. Describe the change control, source code contro!, and media control procedures.

- Problem reporting procedures - describe the procedures for reporting defects.

- Project library procedures - describe the procedures for entering items into the project library. Define the type of documents that the library will contain.

See Appendix J, Software Management, for more suggestions on managing the software. 


\subsubsection{Purchased Software}

When the development takes place internally, the KCD staff has control over the project and the SQA Team has opportunities to review the development process as the project progresses from stage to stage. But what of the situation when KCD is purchasing software packages? The philosophy of the SQA Plan essentially remains the same, but the number of review and audit points becomes more limited.

Regardless of whether software is purchased or internally developed, an SQA Plan can be developed for it. However, depending on the circumstances, the contents and emphasis of the Plan can vary greatly. In the case of vendor-supplied software, some sections of the Plan outlined above can be omitted or touched on lightly. There is na formula based on software type for determining what should or should not be included in the Plan, but in most cases it will be reasonably clear when it comes time to develop the Plan.

For example, in the case of packaged software, the Plan will still contain the following:

Introduction,

Project Description,

Project Life Cycle,

Deliverables,

Quality Factors,

Reviews, Audits,

Acceptance Testing, and

Software Management.

The difference is that these items vary in scope due to the nature of the project.

There are three basic categories of purchased sottware when dealing with SQA:

1. Off-the-shelf packaged software that requires no changes or where no changes are possible,

2. Software packages that require customizing and configuration services before they are ready to be used, and

3. Totally custom software systems.

See the Appendix K, Purchased Software, for SQA strategy for purchased software.

\subsection{Verification/Validation Reports}

The second set of documents provicied by the SQA Team are the Verification/Validation Reports. 
The results of the reviews, audits, and acceptance tests are documented through the Verification/Validation Reports. They should note any deficiencies that could inhibit the acceptance of the reviewed document or the completed software requirement. This provides a unique opportunity for deficiencies to be captured on defect reports and analyzed so that subsequent improvements can be made in the software development process.

In general, Verification/Validation Reports are used to record the acceptance of the delivered documents and the success or failure of each requirement tested. The SQA Team writes Verification/Validation Reports after each review, audit, and acceptance testing session. Thay distribute the reports to management.

There are several examples of Verification/Validation Reports available. THE Guide has examples of Verification/Validation Reports and other forms which might be of use,

\subsection{Acceptance Test Plan}

The primary goal of acceptance testing is to confirm that the system fulfills the client requirements and solves the problem that originally necessitated starting the project. The Acceptance Test Team, therefore, must work with the clients of the system i.. order to create a useful set of tests that deal with the original objectives of the system.

The Acceptance Test Plan describes the testing environment, test start-up procedures, and specific test cases necessary to verify the adequacy of the system and to formally accept the system.

It is the responsibility of the Acceptance Test Team to develop Acceptance Test Plans for newly created or modified systems whenever the end-client organization exists within KCD. Typically, this situation occurs when a custom system is designed and built by a KCD software development organization for some KCD client organization. In this case, the Acceptance Test Team acts as a representative of the client organization to confirm the adequacy of the completed project by developing an Acceptance Test Plan.

The Acceptance Test Team is also involved with acceptance testing when KCD is the customer of any vendor supplied software.

The approach of the Acceptance Test Plan is to test the external behavior of the system (black-box testing); it is not necessarily concerned with the internal workings of the system. This implies that the Plan should be organized by requirements rather than by hardware/software components. It must contain a detailed set of tests that exercise the various aspects of each requirement. The tests should include normal as well as unexpected operating conditions. Tests should incorporate cases for entering both valid and invalid responses. 
Each test case and the test results should be carefully tracked. Tests can fail several times before they are completely corrected and accepted by the Acceptance Test Team. Various modules can be in different states of testing and quickly become confused without careful tracking and documentation.

It is the responsibility of the Acceptance Test Team, after every Acceptance Test session, to compile the results and distribute it to the appropriate parties.

See Appendix I, Acceptance Testing Procedures, for additional information. 


\subsection{CONCLUSION}

"A thousand mile journey begins with the first step."

This handbook is the start of a long-term process to help achieve quality software. When you use the handbook, realize that it is a means to the end, not the end itself. It certainly is not intended to be a stand-alone document. The handbook is not a procedure to be followed step-by-step. It is -- as suggested in the preface -- a living document which was "built" to be modified.

The Software Quality Assurance Group will be happy to help you with any SQA questions or problems. Please contact us if you want our help or if you have any comments about the handbook. 


\section{Appendix A KCD SQA}

\section{BACKGROUND}

A Software Quality Assurance (SQA) Group was formed within the Quality Division at KCD in July, 1988. The group members were from various computer-usage backgrounds. They are dedicated resources and are chartered to guide the plant's SQA policy and efforts.

\section{CHARTER OF THE GROUP}

Purpose:

The purpose is to provide guidance and interpretation on SQA issues by a group which is independent of existing line organizations.

\section{Objectives and responsibilities:}

- Improve the quality of software at KCD.

- Develop and maintain policy for software quality plans covering all KCD developed or procured software.

- Maintain awareness of and participate in the development of emerging software quality activities such as standards, metrics, methodologies, and tools.

- Guide, promote, and participate in the development of software quality assurance training programs for internal use.

- Assist line organizations in the development of detailed programs and plans that meet software quality policy requirements.

- Assist in decisions, mechanics, and risk analyses regarding the degree of software quality control and assurance at the application level.

- Assist the audit function on SQA issues.

- Be the focus for DOE on SQA issues.

- Monitor ongoing software development and procurement changes within KCD. 


\section{RESPONSIBILITIES}

The following diagram displays the relationship between the primary SQA activities and the organizations in the Kansas City Division.

\begin{tabular}{|c|c|c|c|}
\hline \multirow{2}{*}{$\begin{array}{c}\text { SQA } \\
\text { Activity }\end{array}$} & \multicolumn{3}{|c|}{ Responsibility } \\
\hline & $\begin{array}{c}\text { SQA } \\
\text { Function }\end{array}$ & $\begin{array}{c}\text { Line } \\
\text { Organization }\end{array}$ & Quality \\
\hline Policy & $\mathbf{X}$ & Comply & Review \\
\hline Policy & $\begin{array}{l}\text { Assist } \\
\text { Train }\end{array}$ & $\mathbf{X}$ & Review \\
\hline Project (QC) & Guide & $\mathbf{X}$ & Review \\
\hline Audit (QA) & Assist & Comply & $\mathbf{X}$ \\
\hline
\end{tabular}

\section{$\mathrm{X}=$ Primary Responsibility}




\section{Appendix B QUALITY FACTORS}

As defined earlier Quality factors can be grouped according to performance, design, or adaptation concerns. Each quality factor is then composed of attributes, which the SQA Team uses to determine if the extent of the quality for each factor is adequately exhibited. Three attributes are common to many of the quality factors:

- Modularity - The characteristics of the software which provide a structure of highly independent modules;

- Self-descriptiveness - The characteristics of the software provide explanation of the implementation of a function; and

- Simplicity - The characteristics of the software which provide definition and implementation of functions in the least complex and most understandable manner.

\section{Performance Quality Factors}

\section{Efficiency}

Efficiency is concerned with software utilization of resources. The three attributes of efficiency are these:

- Effectiveness communication - The characteristics of the software which provide for minimum utilization of communications resources in performing functions;

- Effectiveness processing - The characteristics of the software which provide for minimum utilization of processing resources in performing functions; and

- Effectiveness storage - The characteristics of the software which provide for minimum utilization of storage resources.

\section{Integrity}

Integrity is concerned with system security. The attribute that describes integrity is

- System accessibility - The characteristics of the software which provide for control and audit of access to the software and data. 


\section{Reliability}

Reliability is concerned with what confidence can be placed in the software. The attributes which describe reliability:

- Accuracy - The characteristics of the software which provide the required precision in calculations and outputs;

- Anomaly management - The characteristics of the software which provide for continuity of operations under and recovery from adverse conditions; and

- Simplicity.

\section{Survivability}

Survivability is concerned with how well the software will perform under adverse conditions. The attributes which support survivability:

- Anomaly management;

- Autonomy - The characteristics of the software which determine its non-dependency on interfaces and functions;

- Distributedness - The characteristics of the software which determine the degree to which software functions are geographically or logically separated within the system;

- Reconfigurability - The characteristics of the software which provide for continuity of system operation when one or more processors, storage units, or communication links fails; and

- Modularity.

\section{Usability}

Usability is concerned with the system ease-of-use. The attributes which describe usability:

- Operability - The characteristics of the software which determine operations and procedures concerned with operations of the software and which provide useful inputs and outputs which can be assimilated; and

- Training - The characteristics of the software which provide transition from current operation and provide initial familiarization. 


\section{Design Quality Factors}

\section{Correctness}

Correctness is concerned with how well the software conforms to the requirements. The attributes involved in achieving correctness are these:

- Traceability - The characteristics of the software that provide a thread from the requirements to the implementation with respect to the specific development and operational environment;

- Consistency - The characteristics of the software that provide uniform design and implementation techniques and notation; and

- Completeness - The characteristics of the software that provide full implementation of the functions required.

\section{Maintainability}

Maintainability is concerned with how easy the software is to repair. The attributes involved in achieving maintainability are these:

- Consistency;

- Visibility - The characteristics of the software which provide status monitoring of the development and operation;

- Modularity;

- Self-descriptiveness; and

- Simplicity.

\section{Verifiability}

Verifiability is concerned with how easy it is to verify the software performance. The attributes which support verifiability are these:

- Visibility;

- Modularity; 
- Self-descriptiveness; and

- Simplicity.

\section{Adaptation Quality Factors}

\section{Expandability}

Expandability is concerned with how easy it is to expand or upgrade the software capability or performance. The attributes which support expandability are these:

- Augmentability - The characteristics of the software which provide for expansion of capability for functions and data:

- Generality - The characteristics of the software which provide breadth to the functions performed;

- Virtuality - The characteristics of the software which present a system that does not require client knowledge of the physical, logical, or topological characteristics;

- Modularity;

- Self-descriptiveness; and

- Simplicity.

\section{Flexibility}

Flexibility is concerned with how easy it is to change the software. The attributes which describe flexibility are:

- Commonality - The characteristics of the software which provide for the use of interface standards for protocols, routines, and data representations;

- Functional overlap - The characteristics of the software which provide commonality of functions among applications;

- System compatibility - The characteristics of the software which provide the hardware, software, and communication compatibility of two systems;

- Self-descriptiveness; and

- Modularity. 


\section{Portability}

Portability is concerned with how easy it is to transport the system. The attributes which describe portability are these:

- Independence - The characteristics of the software which determine its non-dependency on the software environment (operating systems, utilities, input/output routines, libraries);

- Self-descriptiveness; and

- Modularity.

\section{Reusability}

Reusability is concerned with how easy it is to convert the software for use in another application. The attributes which suyport reusability are these:

- Application independence - The characteristics of the software which determine its non-dependency on data base system microcode, computer architecture, and algorithms;

- Document accessibility - The characteristics of the software which provide for easy access to software and selective use of its components;

- Functional scope - The characteristics of the software which provide common functions to both systems;

- Generality;

- Independence - The characteristics of the software which determine its non-dependency on the software environment (operating systems, utilities, input/output routines, libraries);

- System clarity - The characteristics of the software which provide for clear description of program structure in a non-complex and understandable manner;

- Modularity;

- Self-descriptiveness; and

- Simplicity. 


\section{Interoperability}

Interoperability is concerned with how easy it is to interface the software with another system. The attribute which supports interoperability is

- Modularity. 


\section{Appendix C LIFE CYCLES}

This section describes some of the basic concepts of life cycles and how they affect SQA activities.

\section{C.1 Thought Processes Versus Documer tation Processes}

A life cycle has two main components: the thought process of project development and the resulting creation of documentation. It is important to ui derstand the distinction between the development thought process and the documentation process. The thought process is the cognitive steps that occur during the project. The docilmentation process provides the set of documents created as a result of the thought process. The documentation process takes snapshots of the current state of the thought process. The thought process is relatively. constant from one project to another, but the documentation process can vary greatly. It is impossible to define a single set of documentation that is adequate for all projects.

The life cycle is like an accordion that can stretch or shrink to fit the size of the project. Given a small project, an initial problem statement can be comparatively closer to the code than a larger problem statement that requires more development activities.

Both large and small projects represent software development efforts and both projects require a life cycle. The key point is that both projects do not need the same life cycle. The documentation process for the smaller project should contain fewer steps or snapshots. The size of the project determines whether documentation stages can be combined to make a smaller life cycle or separated to make a larger one.

Remember, regardless of the number of documentation steps, the thought processes should remain essentially the same for both large and small projects. In other words, the developers need to do the same things procedurally and cognitively regardless of the project size. What changes is how these things are presented as documentation.

For example, in a relatively small project it could be acceptable to combine the descriptions of the initial project requirement and the initial solution in a single document. The initial requirement and the initial solution (usually in the form of a functional design) should be at the same level of abstraction, so it is reasonable to have them both described in the same documentation.

On larger projects, it is important to separate the two aspects and develop separate documents: one for requirements and another for the functional design. In the case of very large projects more than one level of a document is considered reasonable. For example, requirements analysis and definition could be documented in two or more stages with each subsequent document describing the requirements at lower levels of abstraction. The same could be true for the functional specification. This can result in two requirements specifications, two functional specifications, etc. 
In the later stages of development, depending on the size of the project, combining the separate architectural and detail designs becomes an issue. After the detail design stage, the subsequent stages essentially stay the same.

\section{C.2 THE Guide's Life Cycle}

THE Guide describes a system development and project management methodology used at KCD.

THE Guide defines its system development life cycle in the following nine phases:

I. Initiate the project.

II. Analyze the existing situation.

III. Define new system requirements.

IV. Design the logical system.

V. Design the physical system.

VI. Construct the system.

VII. Test and implement the system.

VIII. Use the system.

LX. Maintain the system.

SQA activities are specified in the phase descriptions of the THE Guide. The following sections describe each phase in more detail. Included are some additional thoughts that may not be covered in THE Guide.

\section{C.2.1 Phase I - Initiate tike Project}

This stage includes the activities that precede the official start of a project. This phase is based on the concept of clearly defining the problen and objectives with the client before proceeding blindly to solutions.

Once management approval is obtained, the Project Team is established and SQA planning begins. The documentation can include workshop notes, a preliminary study, and an initial project plan.

\section{C.2.2 Phase II - Analyze the Existing Situation}

In this phase, system developers look at the clients' environment, including existing and planned systems that relate to the proposed project. This helps to accomplish several things.

- It incorporates the clients' past experience into the project. 
- It provides an understanding of the ramifications of a new system on the organization.

- It develops a perspective of the required solution.

- It ensures that the solution fits the corporate environment.

- It seeks to build rapport with the client while documenting the current system.

In this stage, early problems are usually discovered and many are solved quickly. With the existing system well documented and its problems clearly understood, an orderly, systematic evaluation can then take place.

During this phase the context of the existing system and the "why" of the new system is addressed. Its purpose is to establish a common vision for the objectives and direction of the project, obtain a commitment from the client's organization and provide a plan to achieve the solution.

In this phase we need to understand the potential ramifications of installing a new system in an existing, functioning organization. The goal is to create a system compatible with both existing company systems and future company plans. The result of this stage is an awareness by the Project Team and the SQA Team of the vision, the form, and the direction that the system solution should take.

The resulting document is used as a reference by developers to avoid building a new system that does not alleviate the old problems. The documentation that can result frorn this phase includes the evaluated benefits, existing system functional documentation, existing system data documentation, and organizational impact studies.

\section{C.2.3 Phase III - Define New System Requirements}

The requirements stage formalizes the clients' functional and system requirements to define what the new system should contain. Extensive interviews with the client team are held to identify new functional requirements and determine how present systems fit into future solutions. This may establish hardware and software fourdations upon which the applications will run -- for instance, operating systems, data communications, data bases, graphics support, file management, data development hardware and production hardware.

Defining performance criteria is also necessary at this time. This analysis should address real--time requirements and include physical constraints that can impact the design. It should also focus on those areas that appear to be potential performance bottlenecks.

Defining functional requirements establishes the foundation for the acceptance criteria that will be used at the end of the project. 
A primary goal of the SQA process during this phase is to verify the accuracy of the requirement specification documentation. This accuracy is one of the factors that defines quality and is referred to as correctness. There are three components of correctness: traceability, consistency, and completeness. The accuracy of the requirements specification is critical to the quality measurements used throughout the rest of the project. Therefore, it is important for the SQA Team to work hard to verify that correctness is being achieved in this early stage.

The documentation that results can include general requirements, performance requirements, subjective requirements, constraining requirements, data requirements (data model), functional requirements, preliminary data flow diagrams, entity relationships, state transitions diagrams, a data dictionary, and a requirements specification report.

\section{C.2.4 Phase IV - Design the Logical System}

This phase contains all the activities that are part of the effort to build a conceptually correct system. The logical design describes a system that solves the client's problem. Its description must begin at the same level of abstraction as the description of the requirement and move downward in more detail.

The clieni's view plays an important role in this phase. Various client scenarios describe for the client how the system will solve the problem. System developers may create a visualization of the final system by a method called prototyping.

A. prototype is a model of a system on which later versions are based. Often prototypes will be discarded rather than implemented as built. Prototypes are used in software development to check whether the system under development meets the primary requirements.

Beyond prototyping, developers need to address numerous aspects of the design. The main activities that occur during this stage involve defining functional components, determining major data base tables and the data structures design, designing testing tools, and investigating technical feasibility and sizing. The documentation generated from this stage, as defined in THE Guide, is the logical functional design, the logical data design, the published logical system design, and project recommendations.

\section{C.2.5 Phase V - Design the Physical System}

This stage involves describing the system solution in terms of software process layers and reusable modules. System designers in this phase define transactional data flow between components and use tools such as data flow diagrams, state transitions, data dictionaries and higher level structure charts. Typical documentation resulting from this stage, as defined in THE Guide, are as follows: 
1. Physical input, output, and data structures;

2. Physical data tlow diagrams, data structures, and partitions;

3. Data base modifications;

4. System test procedures; and

5. Physical system design documents.

\section{C.2.6 Phase VI - Construct the System}

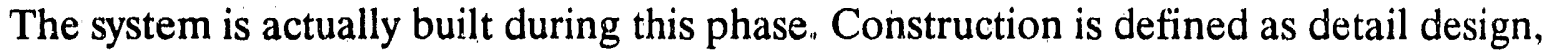
coding, and unit testing of programs. This means that the test data and files are constructed at this time.

The products of system construction are executable, fully tested application programs. Development of a client training program can also begin during this phase so that training can proceed as part of integration. Client and operator training can begin as soon as it is feasible.

Detailed design includes covering the description of the system solution in the form of software modules, algorithms, and detailed data structures. The method of documentation includes structure charts, module descriptions, and pseudo code or structured English. 'Typical output from this stage includes accepted application programs, system files, program test data, and support documentation.

\section{C.2.7 Phase VII - Test and Implement System}

The project is officially ended with the completion of this stage. The three main activities that occur are these:

- Integration of the software components and corresponding testing as you integrate,

- Installation of the completed system and its integration with other major systems, and

- Acceptance testing of the completed system.

Testing is the key activity in this stage, and the SQA and Acceptance Test Teams are heavily involved. Testing is the means of verifying that what you have built is correct with respect to the specifications that have been created throughout the development process. For each stage of development, from requirements to code, a corresponding test step can be defined. 
For example, unit testing confirms the algorithms defined in the code. Process testing confirms the modules described in detail design. Integration testing confirms the component definition in your physical design. System testing confirms the function described in your logical design. Acceptance testing confirms that the system solves the original problems defined in the requirements. Completion of the project is accomplished by installing the newly developed system, testing it, and demonstrating that it meets the requirements and solves the initial problem. Some of the outputs of this phase are the new working system, system support documents and an evaluation of the project.

\section{C.2.8 Phase VIII - Using the System}

Operations is the day-to-day use and associated support of the installed system at the client site. Developers of the system are normally responsible for providing the Client Manual and Maintenance Guide, setting up the source code control mechanisms, and generally being responsible for the software configuration before the system is officially turned over to the clients. Regardless of whether it is an internal or external system, when an enhancement or modification to the software needs to be made, the life cycle begins again (in phase nine, Maintenance).

\section{C.2.9 Phase IX - Maintenance}

Maintenance is the final stage and deais with changing the software system. This leads to the beginning stages again. Here we deal with enhancements or modifications to the software and address questions such as why we need the change, what the requirements of the change are, what the functions associated with the change are, and how we will implement it. This causes us to go through the life cycle again. 


\section{Appendix D SQA TEAM}

\section{D.1 Structure}

Each SQA Team is chosen for a particular project. Its staff structure is organized according to the specific needs of the project and the specific size and complexity of the system being developed. The SQA Team is led by an SQA Administrator who is responsible for managing and coordinating the Team's activities. This person is responsible for seeing that the SQA Plan is developed and executed. The SQA Administrator is also responsible for ensuring the adequacy of the SQA effort.

It is important that the administrator have some project management experience and/or training for this role. As in any position in management, the SQA Administrator must be given adequate authority to carry out the role.

\section{D.2 Roles}

Typically, the SQA Team is made up of the SQA Administrator and several specialists. It can include people who are experienced and skilled in various areas of the SQA function, such as these:

Auditors - Staff who are familiar with software engineering techniques, organizational procedures and are experienced at building software;

Reviewers - Staff who are experienced in the particular application and familiar with analysis and design techniques that are used;

Application Specialists - Staff who are very familiar with the new system's application and who can educate other SQA Team members; and

Scribe - Someone who will record the issues of the reviews and audits, and note problems and action items. 


\section{Appendix E ACCEPTANCE TEST TEAM}

\section{E.1 Structure}

Each Acceptance Test Team is chosen for a particular project. Like the SQA Team, its staff structure is organized based upon the specific needs of the project and the specific size and complexity of the system being developed. The Acceptance Test Team is led by an Acceptance Test Team Administrator who is responsible for managing and coordinating the Team's activities, and for seeing that the Acceptance Test Plan is developed, executed, and properly documented.

Like the SQA Administrator, this person must have some project management experience and/or training for the role. Like anyone in a management position, the Acceptance Test Team Administrator must be given adequate authority to carry out the role.

\section{E.2 Roles}

Typically, the Acceptance Test Team is made up of the Acceptance Test Team Administrator and several specialists. It can include people who are experienced and skilled in various areas of testing and of the project, such as these:

Test Plan Developers - Staff who are experienced testers and who are very familiar with the application;

Testers - Staff who know the application and can follow the Test Plan;

Clients - Staff who know how the system should work and how it will be used;

Scribe - Someone who will record the issues of the testing, note problems, and action items; and

SOA Representative - A member of the SQA Team who will verify that the Acceptance Test Plan was executed and documented properly. 


\section{Appendix F SOFTWARE METRICS}

Part of the SQA Group's responsibilities, as stated in the charter (see Appendix A, KCD $\mathrm{SQA}$ ), is to improve the quality of software at KCD. Improvement of quality implies knowledge of what currently exists as a measured baseline. The baseline measurement must be in an objective and quantitative format. It is the responsibility of the SQA Group to help develop metrics and support their use. Metrics show tangible proof of the correlation between quality methods and improved software. In other words, metrics should help verify how changes to the software process affect the overall quality that can be achieved.

\section{F.1 Examples}

There are many types of metrics which can be associated with software at various stages and levels. We have included some examples.

\section{Defect Reporting}

Defect data, as previously discussed in the SQA strategy, can be collected at all stages of the life cycle and at all levels of software. Comparing defect counts to function points can be a useful measure of quality trends. Function points are a standard measure of system size from the client's perspective. In addition to defect counts, another quality measure could be the amount of time spent finding and correcting various types of defects.

\section{Complexity Metrics}

At the program level, complexity metrics have been found to be useful in forecasting reliability and maintenance requirements. Preliminary results have shown that the number of program errors that are hard to find and correct correspond directly to the level of complexity. The greater the complexity, the greater the potential for errors. This metric measures the flow of control through the program and views the flow as a set of directed graphs. There are different approaches for calculating these complexity metrics. However, they are beyond the current scope of this handbook. See Appendix $\mathrm{N}$, Bibliography, for suggested reading material.

\section{Boeing Metrics}

The Boeing Metrics can be used to measure the extent to which the quality factors were applied to the different stages of software. The Boeing Metrics offer a list of useful questions to be considered when looking for specific quality characteristics in the software. 


\section{F.2 Use of Metrics}

Software metrics should be used carefully and with much thought. The science of software metrics is still new and somewhat limited. Also, metrics should not be used to evaluate people, because that will destroy the honest and consistent inputs needed from all individuals. The use of metrics can possibly be automated with CASE (Computer Aided Software Engineering) tools.

Much has been written about software metrics and their uses. This section of the handbook will eventually grow as the maturity level of metrics increases at KCD. See Appendix N, Bibliography, for suggested reading material. 


\section{Appendix G REVIEW PROCEDURES}

Reviews are used to determine if the current phase of the project life cycle is complete and the project can proceed to the next phase. Reviews are led by the SQA Team but both the Project Team and the SQA Team participate.

The review differs from an audit in that the review ensures the quality of the technical solution while the audit verifies that the process and its documentation are in accordance with the SQA Plan and organizational procedures.

Through the review process the reviewers determine whether the system under development is acceptable and the documentation is complete and satisfactory. If it meets all the requirements for quality, the SQ.A Team accepts the document and recommends proceeding to the next stage of development. If, during the review, the document is found to be inadequate or lacking the necessary quality factors, the SQA Team reports it to the developers and recommends appropriate changes before the project can proceed.

\section{G.1 General Review Procedures}

Before a scheduled review, the SQA Team usually meets by themselves to read any documentation and check for quality factors. They note issues, concerns, and questions to bring to the review. A concern is a comment, question, or suggestion that is not of sufficient importance to slow the progress of the project or cause another review. An issue is an error, problem, or disagreement. An issue forces another review to ensure that the identified changes actually resolve the problem.

The following steps provide more details of the review process.

1. The SQA Administrator is the chief coordinator for an upcoming review. When the Project Team has completed a deliverable that the SQA plan identifies for review, they inform the SQA Administrator, who, in turn, schedules the review with the appropriate people.

2. Before the review, the deliverable is distributed to the reviewers. Each reviewer studies the material to identify any errors in the document. In addition, the SQA Team reviews the deliverable to verify that the quality factors are satisfied and identify areas that do not meet SQA standards.

3. The SQA Team provides the Project Team with a list of any questions or issues (especially SQA ones) that were identified in preparing for the review. When the Project Team has the information before the review, they can check their documentation properly and prepare for the meeting.

4. The review is then held, with an SQA Team member present. Notes are taken of the issues and concerns. 
5. Next, the SQA Team meets with the Project Team and discusses the issues and concerns about the deliverable. This meeting is to clarify the issues, to inform the Project Tearn about the status of acceptance of the deliverable, and to address the action items required to bring the document into conformance.

6. After the review, the SQA Administrator documents that the review has taken place. This may be done by completing a formal Evaluation Form. The SQA Administrator records either the acceptance of the deliverable or lists the problems and action items required to rectify the deficiencies. The documentation of the review should identify:

Project name;

Life cycle phase and activity;

Document reviewed;

Date of the review;

Project Team participants;

SQA Team participants;

Roles of the participants;

Results of the review (Accept, Conditional, Unacceptable);

Concerns, if any;

Issues, if any; Required action items, if any;

Schedule for next review of the document, if needed; and

Schedule for completion of required action items.

The SQA Administrator distributes the Evaluation Form to the appropriate KCD and Project Team management. This form is one of the Verification/Validation Reports (refer to the Verification/Validation Reports in the Documentation section).

\section{G.2 Specific Reviews}

There are several types of reviews for documentation that coincide with the transition from one life cycle phase to another. Documents from three general categories are included: requirements analysis documentation, design documentation, and implemented system deliverables.

Requirements analysis documents are reviewed after deliverables are completed in the early phases of the life cycle. THE Guide detines these phases as project initiation, existing system analysis, and new system requirements. The design reviews take place during the logical and physical design phases. The construction reviews occur during system construction, testing, and implementation. Finally, there are management reviews to check the project plan for adherence to the organizational guidelines.

The specifics of the various reviews in each of the categories are discussed in more detail in the following sections. 


\section{G.2.1 Project Initiation Review}

The Project Initiation Review occurs after the project has been established. This review is important to verify that the project has a proper foundation. The objectives for reviewing the documentation delivered from the Project Initiation Phase are as follows:

1. Verify that the proposed software project is in fact the best approach to the perceived need;

2. Verify the economic and overall feasibility of the project;

3. Ensure that all members of the Project Team, clients, developers, testers, and management share the same understanding of the system requirements and objectives and are using the same terminology;

4. Ensure that the initial system analysis is sufficiently detailed to permit moving to the next stage;

5. Verify that the appropriate software quality factors are adequately addressed in the initial project documentation; and

6. Verify that the appropriate resources have been used to build the proper Project Team.

\section{G.2.2 Context Analysis Review}

The Context Analysis Review takes place at the end of the "Analyze Existing Systems" phase. It confirms that the developers understand the goals of the new system. Reviewing context analysis documentation should accomplish three things.

1. Verify that the systems analysts have clarified the program and identified the main driving forces of the project.

2. Verify that design objectives have been identified and prioritized. Design objectives can include:

Product quality improvement.;

Market responsiveness;

Effective inventory management;

Reduced cost to market; and

Potential standardization.

3. Ensure that the context analysis has properly investigated the existing environment and perspectives. 


\section{G.2.3 New Systems Requirements Review}

The reviews of the documentation of the new system requirements look at the accuracy of the requirements and attempt to accomplish the following:

1. Obtain the organization's commitment to build the proposed software system;

2. Ensure that the system requirements are of sufficient depth and detail to permit initial system design;

3. Verify that the appropriate software quality factors are adequately addressed in the requirements documentation;

4. Verify that the documentation remains consistent as it describes the different abstraction layers in the system; and

5. Confirm that the Project Team has properly used analysis tools to accurately describe the requirements, including data flows, state transitions, and entity relationships. (Refer to the software engineering literature for the description of these documentation tools.)

\section{G.2.4 Logical and Physical Design Reviews}

The design reviews for Phases IV and V, Logical Design and Physical Design, are similar enough to be described together. Design reviews take place as the design documents are produced. The primary purpose of the reviews is to confirm that the design of the system adequately meets the requirements defined in the previous phases. In general, the objectives of these reviews are as follows.

1. Verify that the design documents are complete and are in accordance with the established requirements.

2. Verify that the documents are in sufficient detail to proceed with implementation and installation.

3. Verify that the appropriate software quality factors are adequately addressed in the design documents.

4. Verify that the proper planning for software testing and installation is taking place.

5. Verify that the design tools have been used properly to accurately describe the design. This includes such things as structure charts, pseudo code, and data structure designs. Refer to the software engineering literature for the description of these documentation tools. 
6. Verify that the documentation remains consistent as it describes the different abstraction layers of design within the system.

\section{G.2.5 Software Construction Keviews}

Construction reviews check the software and documentation that is generated during detailed design, coding, and testing phases (Phase VI, System Construction, and Phase VII, Test and Implementation, of THE' Guide's life cycle).

During testing and installation of the system, review of the final delivered documentation is primarily review of manuals, particularly the Client Manual and the Maintenarice Manual.

\section{Detail Design--Code Walkthroughs}

The review that occurs during the construction phase is referred to as a structured walkthrough. Structured walkthroughs offer an effective approach to detail design and source code quality checks with as little interference as possible to the developers. It also brings the developers into the SQA effort. Getting the developers involved in the quality process improves the chances that they will accept the reviews and see them as positive.

It has been shown that peer reviews during system development are approximately five times more effective than conventional run-time testing techniques.

Typically, reviews involve both SQA Tearn members and technical staff members. The developer of the components under review selects experienced technical staff members to act as reviewers. Ideally, the reviewers are not from the same project; this allows a fresh perspective and greater objectivity. In addition, someone from the SQA Team acts as an observer to confirm the adequacy of the walkthrough process and to determine the adequacy of the code quality, based upon their observations in the walkthrough meeting. The SQA Team member reports the issues in a Verification/ Validation Report. If the walkthrough reveals deficiencies in the software, they are corrected and, if necessary, the walkthrough is performed again.

The key to the walkthrough is not to search for faults in the programmer but rather in the code. An experienced person acts as the moderator for the discussion. Walkthroughs should provide an environment to promote good discussions.

Use only enough structure in the meeting and enough moderating in the discussion to keep the walkthrough moving and productive. Source code should be distributed to the reviewers several days in advance to allow time to scan the code for readability, style, and flow. 
The walkthrough usually starts with the programmer presenting the overall design and structure of the code under review. The reviewers then ask questions and review quality characteristics regarding

\author{
Logic details, \\ Accuracy, \\ Level of complexity, \\ Level of readability, \\ Approach, \\ Style, and \\ Efficient use of code.
}

At the same time, the reviewers check for: syntax and semantic errors and punctuation mistakes. Finally, the reviewer's, including the SQA Team members, apply the appropriate quality factors to see if the design and code under review adequately till the criteria. Typically, things like modularity, simplicity, and maintainability are key factors used during the walkthrough process to confirm the quality of the software.

Of all the factors, maintainability can be the key for checking quality. It has been shown that if a routine is particularly complex and appears to be difficult for someone else to maintain, then chances are that the routine will be difficult to test and debug. Therefore, quite often, developing an opinion about the maintainability of a routine can help lead to determining the routine's overall adequacy for quality.

Someone in the walkthrough acts as the scribe to record comments, suggestions, and expected corrections and modifications. Often, the ideas come fast and are sometimes disjointed, so someone needs to record the important points and action items.

If the SQA Team determines that major changes in the design and/or code are needed, then they schedule another walkthrough after the moditications have been completed. Regardless of the outcome of the walkthrough, the SQA Team fills out a brief report to be placed in the library and copied to the project for purposes of updating schedules. The walkthrough or review report should contain the following items:

1. List of modules reviewed,

2. Author of the code and list of attendees at the review,

3. Date that the review took place,

4. A brief description of the walkthroughs issues and a list of modifications that are expected to be made (if any) for each module and expected date of completion, and

5. A determination of the adequacy of the software (pass/fail). 
Walkthroughs are a form of review and should be done whenever a component of the system under development has reached the detail design and coding stage. The number of modules to be reviewed during a walkthrough should be carefully controlled. Walkthroughs of just a few modules result in brief reviews bitt can require too many walkthrough maetings to review the whole system. On the other hand, a session with too many modules can take too long, cause fatigue, and reduce the efficiency of the walkthrough.

As a rule of thumb, a good review takes two to four hours. Certainly, try to keep all reviews under one day; otherwise in the last hours of a walkthrough, the reviewers are too tired to effectively catch errors.

When a walkthrough results in unanswered questions about requirements or high-level design, it may be necessary to take a step backward and review the requirements and logical/physical designs to resolve outstanding issues. This should be done before proceeding to coding and testing.

The walkthrough format may be varied to involve more formalization and role playing. Members of the walkthrough are assigned a special role in the review process. For example, they could represent the client group, the testers, the moderator, or the maintenance group.

Experimenting with walkthroughs will help determine what is the most effective way to conduct them. Historically, offering flexibility in the procedure with well-directed goals and guidelines has proven to be a gond approach.

To be most effective, walkthroughs of any type must be conducted in the open, non-defensive climate that is required for all reviews and audits. They should find discrepancies in the code but not blame programmers. Developers must see this process as a constructive and useful tool for them to create better software. Postpone assessing programmer ability to a later time and a different forum.

\section{G.2.6 Manuals Review}

There are two general categories of manuals: Client Manuals and Maintenance Guides.

\section{G.2.6.1 Client Manual Reviews}

System operators and clients read the Client Manuals to learn how to configure, start up, use, and shut down the system. The client manual review takes place as each manual is completed and delivered. The purpose of the review is to confirm that the client interface adequately meets system requirements and satisfies the quality factors defined in the SQA Plan. The SQA Team conducts the review. 
The primary activities in this review are

1. Read the manuals for readability and usability as both a training aid and a reference manual; and

2. Check for accuracy by going through the manuals while at the client's terminals and comparing the manuals with the actual running system.

\section{G.2.6.2 Maintenance Guide Review}

The Maintenance Guide contains the latest structure and contents of the system to facilitate changes. Typically, this is useful to the technical staff who were not originally involved in the project's development, and so are unfamiliar with it.

The Maintenance Guide consists of

1. Program road maps

a. Program map - names, descriptions, and location of source code

b. Task maps - same as a program map with activation or task-spawning links shown between tasks

c. Module map - describes modules and shows calling structure

d. Cross reference and link map - generated by compiler/linker

2. Procedures guide - describes the command files used for compiling, linking, loading, and source code control

3. Maintenance considerations - describe those characteristics of the system which should remain constant, including any warnings, suggestions and aids.

The purpose of reviewing the Maintenance Guide is to confirm that the sections of the Maintenance Guide described above exist for this project and that the information is accurate and usable.

Note: Since the program road maps are intended to be created automatically (if possible) by the development computer system, the review does not necessarily need to have the maps. It only needs to confirm the command instructions for generating the maps on the system. However, the procedures guide and the maintenance considerations sections of the Maintenance Guide are written by the Project Team and are necessary during this review. 


\section{G.2.7 Test Plan Reviews}

Test Plan Reviews are reviews of the System Test Plan and the Acceptance Test Plan. Any reviews of test plans are done after completion of the Test Plan and prior to the execution of those plans. The primary objective of these reviews is to verify that the Test Plans are adequate. The SQA Team members conduct the reviews.

The review should

1. Verify that the Plan contains a description of the testing environment, test start up procedures, and specific test cases for the requirements of the system;

2. Confirm the adequacy of the testing environment and testing procedures; and

3. Confirm that the Test Plan has broken the testing down into hierarchical stages that help isolate the functions being tested. 


\section{Appendix H AUDIT PROCEDURES}

Quality assurance audits take place at the completion of major milestones in the development process. This section describes the suggested procedures for audits.

\section{H.1 General Audit Procedures}

The audit differs from a review in that the audit concentrates on the appropriateness of the software engineering process while the review concentrates on the quality of the technical solution. An audit checks the development steps taken so far and confirms that they are in accordance with organizational policies and procedures as well as the SQA Plan. The goal of an audit is to lower risk and reduce maintenance costs by verifying that the project has been properly engineered.

Performing an audit is similar to performing a review. The primary difference is that the SQA Team does not necessarily need to meet beforehand (by themselves) to read any documentation, but instead, meets directly with the vendor and/or Project Team. In the meeting, the SQA Team discusses with the Project Team the process that the developers have taken in creating the system up to that point. Based upon the objectives of the particular audit, the SQA Team investigates to verify that all the proper activities have been executed to an adequate level.

There are four times during a life cycle when an audit can occur. The size and scope of the project will determine how many audits are necessary. The SQA Team defines which audits it will perform on the project during project initiation. Typically, audits are useful at the completion of these activities:

- Project initiation,

- Physical design,

- System testing, and

- Final installation and acceptance.

Regardless of which audit is performed, there are common goals among them.

1. Verify that all documentation is updated to include the latest release of any new technical information or new requirements.

2. Verify that the specifications are complete and conform to specification guidelines.

3. Verify that the SQA Plan reflects an understanding of the critical areas of the project and demonstrates that adequate control is planned to ensure product quality.

4. Verify that the Project Team is organized, managed, and performs to minimize the risk of project failure. 
5. Verify that the project plan has been established defining activities, resources, estimates, dependencies, and schedules, and that updates or changes are properly implemented.

6. Verify that all baseline and documentation updates or changes are properly prepared, submitted, approved, and implemented.

A part of the SQA Team's role is to minimize the potential risk to the success of the project. The Team acts as an objective observer to identify areas of significant risk, such as

- Inadequate staff for the size of the project,

- Inexperienced staff for the complexity of the project,

- Lack of proper development tools,

- Too much untried technology in a single project,

- Inadequate project management to control changing requirements,

- Too much internal politics resulting in changing requirements, and

- Unavailability of the client organization to adequately confirm requirements.

These are some of the typical problems in developing software systems that can have a real effect on a Project Team's ability to create a successful system. During the project audits, should an issue arise that threatens the success of the project, the SQA Team can report its issues in the Verification/Validation Report that is generated at the end of an audit.

\section{H.2 Specific Audits}

The four audits that typically take place during the development of a system are

1. Project initiation audit,

2. Design audit,

3. Functional configuration audit, and

4. Physical configuration audit. 


\section{H.2.1 Project Initiation Audit}

The Project Initiation Audit makes sure that the project has started properly and that the SQA Team has sufficient information to write the SQA Plan.

During the project initiation audit, check to confirm that

- A proper life cycle exists,

- A proper Project Team has been established,

- A project plan has been built,

- The documentation deliverables have been defined,

- The documentation guidelines have been defined,

- The SQA reviews and audits have been defined with the appropriate quality factors and characteristics, and

- The Preliminary Acceptance Test Plan strategy has been identified.

\section{H.2.2 Design Audit}

The Design Audit is conducted at the completion of the logical and physical designs. Its purpose is to verify that the design of the new system is being developed in a proper manner and that appropriate software engineering tools and methods are being applied.

The Design Engineering Audit confirms that

- The proper software engineering techniques are being used,

The adequate resources are being applied,

- The adequate computing resources are made available for implementation, and

- The project plan is being updated and remains relevant.

\section{H.2.3 Functional Configuration Audit}

The Functional Configuration Audit is conducted at the completion of system testing. This audit addresses the function of the software system and verifies that all required 
corrections have been or are being implemented. It also checks to see that the testing was properly conducted and that the test results indicate that the system meets functional and product quality requirements.

This audit should

- Verify that the major software components are properly linked and tested;

- Verify that the system test as conducted represents an adequate set of tests;

- Verify that all documentation has been properly prepared, including any change orders that exist;

- Obtain a current list of known defects and problems;

- Verify that the proper configuration management procedures have been established for system release; and

- Verify that the Acceptance Test Plan is finished and Acceptance Testing is ready to be started;

\section{H.2.4 Physical Configuration Audit}

The physical configuration audit is accomplished at the completion of the acceptance testing of the system. The primary intent of the audit is to verify that the system is ready for operation.

This audit should

- Verify that the final configuration items, as specified in previous requirements and design documents, are all accounted for;

- Verify that the Acceptance Test Plan was properly executed and that it represents an adequate level of testing;

- Verify that all previously reported problems, deficiencies, and defects, have adequate solutions proposed and implemented;

- Verify that all system manuals satisfy the acceptance criteria and are up-to-date, correct, and consistent;

- Verify that all support programs and hardware are in good working order and are in conformance with the final system configuration;

- Verify the existence of a maintenance manual; and

- Verify that proper configuration management procedures have been established for managing changes after the system is operating. 


\section{Appendix I ACCEPTANCE TESTING PROCEDURES}

This section describes the activity of acceptance testing. This activity is primarily directed by the contents of the Acceptance Test Plan. In fact, Acceptance Testing is simply the act of executing the Acceptance Test Plan.

The purpose of acceptance testing is simple: to test the functions of the system and confirm that they work correctly with respect to the delivered design documents and that the system fulfills the specified requirements.

There are three basic ingredients to successful acceptance testing:

- A well developed Acceptance Test Plan;

- Adequate and qualified resources to perform the tests; and

- Careful and deliberate procedures for reporting and tracking the test results.

\section{I.1 Plan Organization}

The Acceptance Test Plan performs black-box testing, which tests only the external behavior of the system. It is not necessarily concerned with the internal workings of the system. The Plan contains a detailed set of tests that exercise the requirements including unexpected conditions.

The Acceptance Test Plan is organized hierarchically by requirements. Within each detail requirement, a series of tests will be identified. Each series could require a special hardware/software configuration to properly test the requirement. In each set of tests, the Test Plan specifies the particular configuration that is needed.

A hierarchical numbering scheme is effective in keeping track of and referencing individual test cases. One alternative for such a scheme is as follows:

\section{\# AA.BB.CC.DD-EE.n}

where:
"AA" is the two digits of the requirement number.
"BB" is the two digits of the detail requirement number.
"CC" is the two digits of the page number which is sequentially ordered within each detail requirement.
"DD" is the two digits of the test number.
"EE" is the two digits of the sub-test number.
" $n$ " is the letter of the test step which is in alphabetical order. 
This numbering scheme implies that the system can be organized into major requirements and second level requirements. For example, shop scheduling would be considered a major requirement. Calendar management and long-term simulation are examples of second-level requirements within shop scheduling.

Likewise, the test cases can be organized into major tests, sub-tests, and test steps. For example, creating a long-term schedule from a list of expected orders is a major test case. Running long-term scheduling under specific degraded operating configurations are examples of different subtests. Specific instances of expected orders and plant equipment operating status are examples of test steps.

For example, test number - 41.01.03-02.b implies:

$\begin{array}{ll}\text { Requirement } & \# 41-\text { Shop scheduling. } \\ \text { Detail Requirement } & \# 1-\text { Long term simulation. } \\ \text { Page } & \# 3-\text { Third page in the testing series. } \\ \text { Sub-test } & \# 2-\text { Degraded operating configurations. } \\ \text { Test Step } & \# \text { b }- \text { One AGV \& one machining center } \\ & \\ & \text { unavailable. }\end{array}$

If it seems that the levels of hierarchy in either the requirements categories or the test cases are not enough, then more levels can be added. Be sure to use as few levels as possible to keep the numbering scheme simple.

An important aspect of preparing the Acceptance Test Plan is determining the appropriate organization of requirements, detail requirements, major tests, sub-tests, and test steps.

Special testing tools or special hardware can enhance the ability to do adequate testing.

\section{I.2 Plan Execution}

Careful and deliberate procedures must be observed while testing. The Acceptance Test Team must remain very organized, because of the enormous number of tests that must be performed. Without organization and the careful tracking and reporting of test results, the Team runs a risk of letting problems slip through the cracks.

Performing the acceptance testing should be relatively straightforward if the Test Plan is properly organized. The Acceptance Test Team loads the testing configuration, follows the procedures in the Plan, and executes each of the test cases that are defined in the Plan on a step by step basis. When a test step passes a test, the testers log it as passed and later note it in the testing results that are given to the SQA Team. When a deficiency in a test is found, the Acceptance Test Team logs the problem and notes the deficiency in the testing results. 
The SQA Team uses those testing results to create the Verification/Validation Report distributed to the Project Team and KCD management at the completion of a testing session. Each testing session can consist of a large number of test cases. The Verification/Validation Report should describe all deficiencies found during that session. The Verification/Validation Report is then used to track the correction activities. 


\section{Appendix J SOFTWARE MANAGEMENT}

This section discusses the activities associated with managing and coordinating the SQA activities, particularly Software Configuration Management, Problem Reporting and Tracking, and maintaining a Project Library.

\section{J.1 Software Configuration Management (SCM)}

A goal of any SQA Plan is to provide a foundation for quality assurance beyond the initial delivery of a system. The Plan provides a mechanism that can be used as the project progresses through enhancements and modifications. In this light, the SQA function includes Software Configuration Management (SCM) as a means to guide the changes that will inevitably occur during and after release of the system.

Configuration Management is seen as a benefit, since it will minimize the potential for misunderstanding when dealing with any changes to the system.

The principle tool of SCM is the concept of a baseline. A baseline is the latest approved version of a document or software component. All proposed changes are made from the context of the latest baseline version. A baseline version will be created at the end of every documentation phase in the project life cycle. The baseline includes source code, configuration data, and final delivered documentation.

Every change that is made to that baseline, until the next baseline is released, must follow SCM procedures. This implies that any changes to the baseline must be formally addressed through the SCM function and, if accepted, added to the sanctioned baseline as an update.

The process of managing and controlling baselines (Software Configuration Management) has five major elements:

1. Software Identification,

2. Software Change Control,

3. Software Administration and Accounting,

4. Source Code Control, and

5. Media Control.

Since our definition of software includes documentation, Software Configuration Management must also be applied to it.

Software Identification is the process by which the SQA Team identifies the specific design documents or the specific software modules that make up the current baseline.

When the SQA Team accepts a completed system, then the current state of the system represents a new baseline that can consist of a single version or a set of baseline 
modules, each with its own identity. Typically, module organizations coincide with requirements. At the time of acceptance of the system, the Configuration Management should be established.

Software Change Control is the process of managing proposed changes to the established baselines. There are two key components for software change control: documenting the changes and reviewing the changes.

Changes to a given baseline can occur for two main reasons: finding a problem in a document review or Acceptance 'Test, and changing requirements. Both kinds of changes must be formally documented before they can be incorporated into the system as part of the new baseline.

Changes are documented through a formal document, a Change Order. Typical items that should be included in the Change Order are

- Title of the change,

- Description (including names of the software modules or documentation),

- Effect on the client,

- Effect on the system,

- Recommended solution or method of change,

- Justification for the change,

- Name and title of the submitting authority, and

- Additional remarks.

To review the changes, an SCM Control Board should be set up with appropriate personnel from the SQA Team, Project Team, client group, and vendors. Their role is to review the proposed changes and decide whether they will be included as changes to the baseline. The board's responsibility is to ensure that the proposed change is sound and to assess the impact, if any, on costs, schedules, and baselines.

Software Administration and Accounting is the process of making sure that accepted changes are properly made to the system and its associated documentation. This function is the responsibility of the SQA Team. A key part of administration is to ensure that changes in the software system are reflected in the client documentation.

The SQA Team will need to provide accurate status accounting of the changes that are occurring between the development of baselines. This is accomplished by maintaining a Configuration Management Log that notes all accepted changes and records their status as the changes are developed, documented, and implemented.

Source Code Control is the function of the system administration. Its purpose is to strictly control software versions in the three states: in production, in testing, and in those versions under development. A software system may have versions of various components in any or all of the three states at any one time. 
Strict control is necessary to keep development and test versions of software separate from production versions. This is accomplished through a source code control system. When a baseline of source code and executables is accepted, a version number is assigned, and the baseline is placed into the configuration management system.

Media Control is a set of procedures that are concerned with the security of the data and the software. It is assumed that standard procedures for backup and secure off-site storage of both data and software exist. It is the role of the Project Manager and the SQA Team to see that each project adheres to the established procedures.

\section{J.2 Problem-Reporting Procedures}

After the system has been officially accepted and shown to be operational, further problems can surface.' KCD management, client management, and Project Team management must agree on a formal procedure for documenting reported defects. The procedure must be simple and effective to reduce the time between discovery of the defect and its correction.

A recommended procedure for reporting defects is that all client personnel have the opportunity to write up a defect report, providing this information:

- Time and date,

- A description of the defect,

- Its related client screen (if any),

- The configuration of the hardware (if pertinent), and

- Any other information that would enable the defect to be reproduced.

When the problem is verified, the Software Change Control procedures specified above will go into effect.

\section{J.3 Project Library}

A project library should be established for every project and should be maintained throughout the duration of the project. This exists so that

- Project audits can be performed,

- New development and SQA staff can quickly become familiar with the project by having all the project information in one place, and 

The project can be used as an historical library to allow future Project Teams
to learn from the experiences of this project.

A set of library procedures should be in established and the project manager is responsible for maintaining a complete history of the project. This includes the following:

- Delivered documentation,

- Specification updates,

- Technical memos,

- Project schedules,

- Status reports,

- SQA Plans,

- Verification/Validation Reports, and

- Team members. 


\section{Appendix K PURCHASED SOFTWARE}

This appendix addresses the three main types of Purchased Software. It also describes how SQA can be addressed for each type, as well as some contractual concerns.

\section{K.1 Packaged Software with No Modifications}

Commercial software packages purchased without custom modifications do not allow access to the source code or any intermediate development activities. Examples are word processors, operating systems, and software embedded in machine controllers or monitors. In such cases, KCD then places the SQA emphasis on acceptance testing and confirms the adequacy of the client documentation. The procedures for acceptance testing can stay the same as for internally developed software, discussed earlier in the handbook.

Since acceptance testing is the only real mechanism for confirming that the software runs properly and is correct, it is important to define correctness for the package.

If the package is sold as a system capable of meeting KCD's requirements, then the Project and SQA Teams document those requirements, build an Acceptance Test Plan for them, execute the Plan, and see how closely the package meets their needs. Just how closely the package matches requirements determines its level of acceptability.

If the package only promises to work as specified in the vendor's Clients' Guide, it is the responsibility of the purchasing parties within KCD to determine if it meets their needs. In that case, the role of the SQA Team is to confirm its correctness with respect to the Clients' Guide, which it uses to build the Acceptance 'Test Plan.

\section{K.2 Packaged Software With Some Modification}

When some customizing and configuration services are necessary before the installation of packaged software, it is important that $\mathrm{KCD}$ require software quality assurance beyond the level required for "Packaged Software with No Modifications." The purchase of software involves the purchase of a quality development process as well as a quality product. The SQA Team must verify that the package modifications and configuration changes are made based upon specific KCD requirements. The SQA Team can do this by requesting access to as many of the development stages as possible. Access to the development process and vendor compliance with KCD procedures should be negotiated items during contract discussions. 


\section{K.3 Vendor-Supplied Custom Software}

This section describes some of the issues associated with applying SQA to vendor-supplied custom software.

In the development of a custom software system supplied by a vendor, it is important to impose the same SQA standards and activities on the vendor that would normally be applied if the project were done in-house. As with vendor-modified packages, access to the development process is a negotiated item during contract discussions. The intent is to have as many review and audit points along the development process as possible.

In addition, there are other SQA issues to address:

- What requirements should the vendors have for performing their own SQA?

- What external SQA requirements must be imposed on the vendors?

As stated earlier, the purchase of software involves the purchase of a quality development process as well as a quality product. $K C D$, as a customer of custom software packages, should require that vendors exercise proper SQA procedures on their own to ensure that the quality of the product is adequate. It is reasonable to expect the vendor to provide proof that such SQA activities are being properly performed. The proof can be in the form of the SQ.A Plan for the development of their systems.

When purchasing software from a vendor, it is important to translate the requirements specified in the Request for Proposal (RFP) and the vendor's proposal into a specification of the deliverables in the Purchase Contract. This can be done by attempting to itemize as many of the functions and requirements of the system and include them as an attachment to the contract or to simply attach the RFP and vendor's proposal as part of the contract.

In such a case, it is important that the RFP and vendor's proposal accurately describe the requirements and provide enough detail to become contractually binding. This means that the RFP should be as specific as possible in what it wants for function. It should also be clear that it expects enough detail in a vendor's proposal to be contractually binding.

In addition, the RFP and vendor's proposal, which now act as the initial requirements definition, should include preliminary quality requirements that are expected of the system. These quality requirements should be based on the quality factors defined earlier.

Regardless of whether a project is a custom system or modifications to an existing package, KCD can reasonably expect a vendor to comply with KCD SQA standards during system development or modification of the package. 


\section{Appendix L THE COMMUNICATION PROCESS}

Communication between the SQA Team and the Project Team is very important for successful SQA. Without successful communication, the quality of the software suffers and the risk of failure on the project rises.

Proper communication between all people involved with the project can be more complicated than many realize. Effective verbal communication should be considered the first skill necessary for performing SQA. Without it, an SQA Team is limited in what it can achieve. It is for this reason that a brief overview of the communication process is included in this handbook. The concepts may seem to be common sense, but it is important that team members be reminded of them. Successful communication is critical to the well-being of the project.

\section{L.1 Improving Interpersonal Communications}

Both sender and receiver must work to improve the communication process. Effective communication is an art, and one that requires careful attention to all elements in the transaction. As a sender in the transaction process, remember to

- Organize your thoughts,

- Give the receiver enough time to understand,

- Use words that he or she can understand, and

- Ask for feedback.

As a receiver in the communication process

- Be attentive,

- Analyze the message and make an active effort to understand,

- Avoid preconceptions, and

- Give feedback.

\section{L.2 Interference}

Interference is the barrier we carry within us during any attempt at communicating. It is the result of our education, social background, and personal disposition. These elements make us who we are as people. However, these elements can act as barriers to successful communication. Here are some examples and recommendations for overcoming them. 


\section{Preconceptions and Opinions}

Opinions generally have a rational basis, but preconceptions tend to be based more on emotion. Both, however, promote the same internal interference -- an idea or an impression formed prior to an actual experience. These preconceptions or biases may be positive or negative. If we are positively disposed to someone, we may prematurely agree to the communication, halting it before it is fully completed. If we feel negatively toward a person, we may halt the communication with a prematurely negative reaction.

One solution is to keep your responses in reserve. Try to keep your mind open and avoid interrupting people while they're speaking. It is important to concentrate on what someone is saying until he or she is finished, and then to form your opinion.

\section{Personality Conflicts}

There will always be people with whom we do not get along. However, we are sometimes forced into a close working relationship with them. When this occurs, our clash of temperaments, personalities, philosophies, and even our life styles can cause us to automatically block out or reject their communication. Overcoming this interference can be difficult, yet it is vital if the team is going to be successful.

The best way of overcoming personality conflicts is to try to see things from other people's perspectives and understand them. If we can't accept them on a personal level, we should try to accept them on a professional level, as fellow workers who are there to help us get our job done. If all else fails, the best course of action is to tactfuliy avoid ciealing with the person, using a third party for communication.

\section{Jargon}

Jargon is the specialized vocabulary of a profession. In the computer field, jargon, at times, can become seriously over-complicated. Some people overuse jargon because they believe that it helps them communicate more effectively. That is usually not the case; much of the jargon should be eliminated.

Sometimes people in technical fields simply have difficulty saying things in plain English. In some cases, people even use jargon in an attempt to impress other people. To overcome jargon, we can tactfully request that the person rephrase his or her communication in less technical terms. Also, try paraphrasing the communication yourself; translate what you think they are trying to say into less technical terms, and then tactfully ask them if that's what they mean. 


\section{Mixed Meanings}

One of the difficult aspects of any human language, such as English, is that words and phrases may have several different meanings, depending on the context of the communications. When double meanings occur they can lead to confusion and serious design problems. Experience has shown that ambiguities occur quite frequently, especially when dealing with complex abstractions such as software design, so be careful.

To determine the intended meaning of an ambiguous communication, notice other signals in the communication such as tone of voice, facial expressions, physical gestures, etc. Next, try to paraphrase the intended communication in a manner similar to that discussed in the paragraph on jargon. This can help clear up any potential ambiguities.

\section{L.3 Feedback}

Another critical element of the communication process is feedback. Here, we are primarily concerned with verbal feedback. Verbal feedback can be divided into four types: opinion, paraphrase, addition, and questioning. The most effective approach in communication efforts uses a mixture of paraphrasing and questioning. For example, if a communication was particularly complex, we can ask for clarification or we can paraphrase. This gives the other person some indication of our understanding of their message and where they are failing to communicate effectively. 


\section{Appendix M KCD SQA POLICY}

Quality software shall be an objective of the quality system and applies to the acquisition, development, use and maintenance of software. The software quality assurance program shall provide assurance that software used is consistent with applicable specifications and shall be directed toward software error prevention. It shall include software that:

-Controls production processes or equipment;

-Controls testing or inspection processes or equipment;

-Controls calibration of standards and measurement devices;

-Provides analysis capability to determine product acceptability; or

-Controls the function of weapon components.

The program shall address, as a minimum:

-Organization, tasks and responsibilities;

- Verification and validation;

-Configuration management;

-Software documentation; and

-Reviews and audits.

Software quality assurance activities shall be commensurate with the complexity and the risk associated with failure of the software to meet established requirements. 


\section{Appendix N BIBLIOGRAPHY}

For further reading on the subject of Software Quality Assurance the following is a list of references.

ANSI/ASQC A3-1978, Quality Systems Terminology, (New York: American National Standard Institute, 1978).

Beizer, Boris, Software System Testing and Quality Assurance, (New York: Van Nostrand Reinhold and Co., 1984).

Bersoff, Edward H., "Elements of Software Configuration Management," IEEE Transactions on Software Engineering, (SE-10, No. 1, Jan. 1984, pp. 79-87).

Boehm, Barry W., et al., Characteristics of Software Quality, (New York: North-Holland, 1978).

Bowen, T.P., Wigle, G.B., and Tsai, J.T., Specifications of Software Quality Attributes, (RADC-TR-85-37, Volumes I-III, Boeing Aerospace Company, Feb. 1985)

Buckle, J.K., Software Configuration Management, (New York: MacMillian, 1982).

Buckley, Fletcher and Poston, Robert, "Software Quality Assurance," IEEE Transactions on Software Engineering, (SE-10, No. 1, Jan. 1984, pp. 36-41).

Connell, John and Linda Brice, "Practical Quality Assurance," Datamation, (March 1985, pp.106-114).

Chow, Tsun S., Software Quality Assurance - A Practical Approach, (Silver Spring, Maryland: IEEE Computer Society Press, 1985).

Fagan, Michael, "Design and Code Inspection to Reduce Errors in Program Development," IBM Systems Journal, (15, No. 3 (1976), pp. 182-211).

Gilb, Tom, Software Metrics, (Cambridge, Massachusetts: Winthrop Publishers, 1977).

Green, T.F., et al., "Program Structures, Complexity, and Error Characteristics," Proceedings on the Symposium on Computer Software Engineering, (New York: Polytechnical Press (1976), 139-154).

Halstead, M.H., Elements of Software Science, (Amsterdam: Elsevier Science Publication, 1977).

IEEE Std 729 -1983, IEEE Standard Glossary of Software Engineering Terminology, (New York: IEEE, 1983).

IEEE Std 730-1984, IEEE Standard for Software Quality Assurance Plans, (New York: IEEE, 1984). 
IEEE Std 983-1986, IEEE Guide for Software Quality Assurance Planning, (New York: IEEE, 1986).

McCabe, T.H., "A Complexity Measure," IEEE Transactions on Software Engineering, (Vol. SE-2, No. 4, 1976).

Myers \& Associates Inc., THE Guide, (Vail, Colorado: 1987).

Siyan, Karanjit, "Coping with Complex Programs," Dr. Dobb's Journal, (March, 1989, pp.60-69).

Vincent, James, Albert Waters, \& John Sinclair, Software Quality Assurance, Volumes

$I \& I I$, (Englewood Cliffs, New Jersey: Prentice-Hall, 1988). 


\section{Index}

\section{A}

Acceptance Test Plan, 15, 23, 61 Acceptance Test Team, 11, 43 Acceptance Testing, 21, 61 Audit, 9

Audits, 20, 57

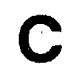

Configuration Management, 65 Correctness, 7, 31

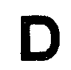

Deliverables, 15, 18

$E$

Efficiency, 6, 29

Expandability, 7, 32

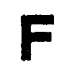

Flexibility, 7, 32

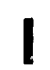

Integrity, 6, 29

Interoperability, 7, 34

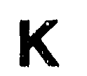

KCD SQA Group, 11, 27

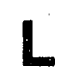

Life Cycle, 7, 18, 35

\section{M}

Maintainability, 7, 31

Metrics, 14, 45

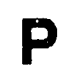

Portability, 7, 33
Problem Reporting, 67

Project Description, 18.

Project Library, 67

Project Team, 11

Purchased Software, 22, 69

\section{Q}

Quality Factor, 6, 19, 29

\section{$\mathbf{R}$}

Reliability, 6, 30

Reusability, 7, 33

Review, 9

Reviews, 20, 47

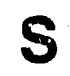

Software, 5

Software Development Project, 9

Software Engineering, 11, 13

Software Management, 21, 65

Software Quality, 5

Software Quality Assurance, 3, 6

Software Validation, 9

Software Verification, 9

SQA, 3, 6

SQA Plan, 15, 17

SQA Team, 11, 18, 41

Survivability, 6, 30

\section{T}

THE Guide, $8,18,19,36,48$

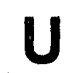

Usability, 6, 30

$$
\text { V }
$$

Verifiability, 7, 31

Verification/Validation Report, 15, 22 

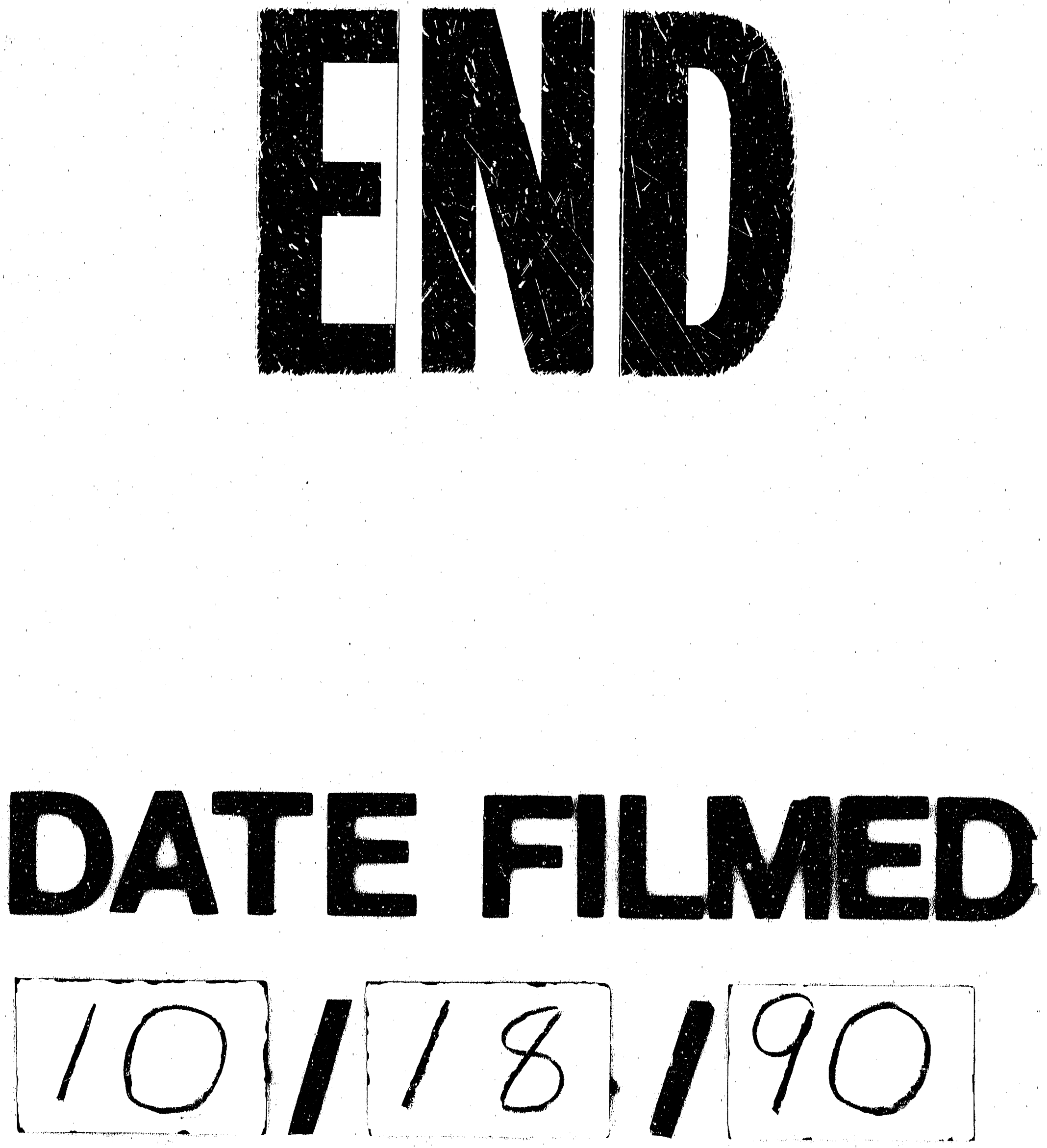
